\title{
Household and community socioeconomic and environmental determinants of child nutritional status in Cameroon Roland Pongou ${ }^{* 1,2}$, Majid Ezzati ${ }^{1}$ and Joshua A Salomon ${ }^{1}$
}

Address: ${ }^{1}$ Harvard School of Public Health, Boston, MA, USA and ${ }^{2}$ Population Studies and Training Center, Brown University, Providence, RI, USA Email: Roland Pongou* - Roland_Pongou@brown.edu; Majid Ezzati - mezzati@hsph.harvard.edu; Joshua A Salomon - jsalomon@hsph.harvard.edu

* Corresponding author

Published: 17 April 2006

BMC Public Health 2006, 6:98 doi:I0.I I86/I47|-2458-6-98
Received: 02 February 2005

Accepted: 17 April 2006

This article is available from: http://www.biomedcentral.com/147I-2458/6/98

(c) 2006 Pongou et al; licensee BioMed Central Ltd.

This is an Open Access article distributed under the terms of the Creative Commons Attribution License (http://creativecommons.org/licenses/by/2.0), which permits unrestricted use, distribution, and reproduction in any medium, provided the original work is properly cited.

\begin{abstract}
Background: Undernutrition is a leading cause of child mortality in developing countries, especially in sub-Saharan Africa. We examine the household and community level socioeconomic and environmental factors associated with child nutritional status in Cameroon, and changes in the effects of these factors during the 1990s economic crisis. We further consider age-specific effects of household economic status on child nutrition.
\end{abstract}

Methods: Child nutritional status was measured by weight-for-age (WAZ) and height-for-age (HAZ) z-scores. Data were from Demographic and Health Surveys conducted in 199I and 1998. We used analysis of variance to assess the bivariate association between the explanatory factors and nutritional status. Multivariate, multilevel analyses were undertaken to estimate the net effects of both household and community factors.

Results: Average WAZ and HAZ declined respectively from -0.70 standard deviations (SD), i.e. $0.70 \mathrm{SD}$ below the reference median, to $-0.83 \mathrm{SD}(\mathrm{p}=0.006)$ and from $-1.03 \mathrm{SD}$ to $-1.14 \mathrm{SD}(\mathrm{p}=$ 0.026 ) between 1991 and 1998. These declines occurred mostly among boys, children over 12 months of age, and those of low socioeconomic status. Maternal education and maternal health seeking behavior were associated with better child nutrition. Household economic status had an overall positive effect that increased during the crisis, but it had little effect in children under 6 months of age. Improved household (water, sanitation and cooking fuel) and community environment had positive effects. Children living in the driest regions of the country were consistently worst off, and those in the largest cities were best off.

Conclusion: Both household and community factors have significant impact on child health in Cameroon. Understanding these relationships can facilitate design of age- and community-specific intervention programs.

\section{Background}

Childhood and maternal undernutrition is currently the single leading cause of the global burden of disease [1]. The fraction of total global health loss attributable to undernutrition was $9.5 \%$ in the year 2000 , and $14.9 \%$ in high-mortality developing regions [1]. In Cameroon, the prevalence of childhood stunting and underweight rose from $23 \%$ to $29 \%$ and from $16 \%$ to $23 \%$, respectively, 
between 1991 and 1998 [2], mirroring the trends in under-5-mortality rates, which increased from 126 per thousand to 152 per thousand between 1991 and 1998 $[3,4]$. Worsening child nutritional status in Cameroon during the 1990s was in line with highest burden of malnutrition in Africa [1], but was opposite to downward trends in much of the world [5], with many countries experiencing growth and nutrition transitions [6]. Understanding the determinants of malnutrition and their trends during periods of declining health is crucial for policy design.

Poor nutritional status reflects an imbalance in dietary intake and/or infectious diseases [7-9], and therefore is affected by multiple environmental and socioeconomic factors such as household socioeconomic status (SES), maternal education, household hygiene, and access to case management in health services [10-16]. Variation by child age in the nutritional effect of household SES and the effect of community-level infrastructure (e.g. hygiene or health service delivery) on malnutrition also have been recognized, but have been investigated in only a few studies [17-19]. Studies combining individual, household and community factors in a single analytical framework are still needed to provide reliable information for policy and program design.

Cameroon is characterized by a marked socio-cultural, economic and environmental diversity likely to cause variations in health and nutrition in children. However, few studies on determinants of child nutritional status have been conducted in Cameroon, and almost all have been in a single district, town or province [20-22]. Further, the variables included in these studies were all at the level of the household, without the inclusion of community characteristics. Therefore the effects of geographical variables and countrywide socioeconomic factors on child nutrition have not been evaluated. Key studies on nutrition and child health conducted at the country or regional level either identified the multiple determinants of health without quantifying their effects in a multivariate framework [23], or estimated the cross-level interactions of particular household and community factors [19], but with no reference to the role of important geographical variables like region of residence, an important predictor of child nutritional status [2] and a notable confounder of the SES-malnutrition relationship in the country. Different regions in Cameroon exhibit different levels of economic development as well as variation in climatic conditions and food production likely to affect child health independently of household or neighborhood economic status $[24,25]$.

In this study, we use nationally representative household surveys from 1991 and 1998 and comparable measures across years to examine the role of multiple household, community, and regional socioeconomic and environmental variables in childhood undernutrition in Cameroon. We include an analysis of how the nutritional effect of household economic status may vary by child age. By considering data from two periods, between which there were important changes in national economy, we also consider how the effects of these determinants may change in response to macroeconomic factors.

\section{Methods \\ Data sources}

Demographic and Health Surveys (DHS) [26] were conducted in Cameroon in 1991 and 1998, designed to be representative at the national, urban-rural and regional level. A two-stage probabilistic sampling technique was used to select clusters at the first level and households at the second level (table 1). The household response rate was $83 \%$ in 1991 and $94 \%$ in 1998 . The survey included a household module, as well as a questionnaire administered to women aged 15 to 49 years, comprising a birth history, information on individual characteristics and health behaviors, and details on their children.

For children alive at each survey (those under age 5 years in 1991 and under age 3 years in 1998), weight and height were measured and used to calculate anthropometric indicators. For the purpose of cross-year comparability, we restricted our study to children under 3 in both surveys. Of the 1966 children born after 1988 and surviving to 1991, anthropometric data were available for 1587 ( $80.7 \%$ of the weighted sample), and of the 2260 children born after 1995 and surviving to 1998, anthropometric data were reported for 1923 (85\%).

\section{Variables}

Child nutritional status is measured by weight-for-age zscores (WAZ) and height-for-age z-scores (HAZ) using the United States National Center for Health Statistics/WHO international reference population. WAZ has been used in many epidemiological studies of undernutrition and child mortality, including in the latest systematic review and meta-analysis [27], and is suitable for the analysis of multiple determinants of child health, including socioeconomic determinants [12]. HAZ is an indicator for linear growth and reflects cumulated and chronic child health conditions. At the individual and household level (referred to as level 1), independent variables included mother's characteristics (education, health seeking behavior, age at child birth, and marital status), household variables (economic status, source of drinking water, sanitation and cooking fuel), and child characteristics (age, sex, size at birth, breastfeeding status and preceding birth interval). Individual and household variables were considered at the same level because there was less than 
Table I: Regional distribution of clusters, households and children

\begin{tabular}{|c|c|c|c|c|c|c|}
\hline & \multicolumn{2}{|c|}{ Clusters } & \multicolumn{2}{|c|}{ Households } & \multicolumn{2}{|c|}{ Children } \\
\hline & 1991 & 1998 & |99| & 1998 & 1991 & 1998 \\
\hline \multicolumn{7}{|l|}{ Regions } \\
\hline Yaounde/Douala & $43(28.8 \%)$ & $43(21.2 \%)$ & $483(13.6 \%)$ & $553(11.8 \%)$ & $260(13.2 \%)$ & $201(8.9 \%)$ \\
\hline West/Littoral & $24(16.1 \%)$ & 39 (19.2\%) & $643(18.2 \%)$ & $780(16.6 \%)$ & $306(15.6 \%)$ & $303(13.4 \%)$ \\
\hline North-West/South West & $19(12.7 \%)$ & $39(19.2 \%)$ & $535(15.1 \%)$ & $923(19.7 \%)$ & $288(14.7 \%)$ & $401(17.7 \%)$ \\
\hline Center/South/East & $23(15.4 \%)$ & 41 (20.2\%) & 669 (18.9\%) & $1045(22.2 \%)$ & 374 (19.0\%) & $527(23.3 \%)$ \\
\hline Adamaoua/North/Far North & $40(26.8 \%)$ & $41(20.2 \%)$ & $1208(34.1 \%)$ & 1395 (29.7\%) & $738(37.5 \%)$ & $828(36.6 \%)$ \\
\hline \multicolumn{7}{|l|}{ Type of place of residence } \\
\hline Yaounde/Douala & $43(28.9 \%)$ & $43(20.7 \%)$ & $483(13.6 \%)$ & $553(11.8 \%)$ & $260(13.2 \%)$ & $20 \mathrm{I}(8.9 \%)$ \\
\hline Other cities/towns & $37(24.8 \%)$ & $50(24.6 \%)$ & $835(23.6 \%)$ & $983(20.9 \%)$ & $518(26.3 \%)$ & $421(18.6 \%)$ \\
\hline Rural & 69 (46.3\%) & $110(54.2 \%)$ & $2220(62.7 \%)$ & $3160(67.3 \%)$ & $1188(60.4 \%)$ & $1638(72.4 \%)$ \\
\hline Total sample size & $149(100 \%)$ & $203(100 \%)$ & $3538(100 \%)$ & $4696(100 \%)$ & $1966(100 \%)$ & $2260(100 \%)$ \\
\hline
\end{tabular}

Notes: -Two clusters in the North-West/South-West region were not surveyed in 1991; so the total number of clusters surveyed was 350 for the two periods.

-The sample sizes for households and children under 3 years old reported in the table are weighted sample sizes; anthropometric measures were taken or were consistent for 1587 children in 1991 and 1923 children in 1998, resulting in a total weighted sample size of 3500 children for the two periods. The non-weighted total sample size was 332 I for children.

-Yaounde and Douala are the largest cities in Cameroon and were sampled separately from other regions and other cities and towns that can be considered as intermediate cities.

one child per household in our data (table 1). Details on the definitions and distributions of these variables appear in table 2.

Household economic status and maternal health-seeking behavior (MHSB) are index variables constructed based on the statistical model developed by Ferguson et al. [28]. The model was designed to measure economic status based on possession of household consumer durables such as electricity, television, bicycle and car. The basic premise of the model is that wealthier households are more likely to own any given set of assets; and that some assets are likely to be consumed at relatively low levels of economic status (e.g. radio or bicycle), while others will be owned only at higher levels (e.g. television or car). The model postulates a continuous level of economic status (unobserved) predicted by a series of socio-demographic covariates (age and sex of the head of the household, mother's education and occupation, and urban or rural place of residence), with observed ownership of each asset captured in a set of indicator variables. The inclusion of certain assets presumed to be owned at roughly the same level on an internationally comparable economic status scale allows comparisons across countries or over time. A similar approach was used to estimate levels of MHSB, with predictive covariates including mother's education and occupation, and place of residence, and dichotomous indicator variables for prenatal visit, tetanus injection during pregnancy, medical assistance at delivery, knowledge of oral rehydration solutions (ORS) and possession of a health card for the child.
Increasing awareness of the effects of community or neighborhood on health beyond individual and household-level influences has produced a vast literature $[29,30]$. In developing countries, community-level factors that may influence health include community economic development, climatic conditions (these two factors are often captured by region of residence) and environmental hygiene. Children residing in clean neighborhoods may have better health than similar children living in unclean neighborhoods. In our study, community statistical units were the DHS clusters sample for the years 1991 and 1998, and community-level independent variables (referred to as level 2 variables) included place of residence, region of residence and environmental status (table 2). Community environmental status is a continuous variable built using pooled 1991 and 1998 datasets and principal components analysis on 5 variables including the proportion of children in households with access to water, sanitation, electricity, using electric stove or gas as cooking fuel, or having finished floor in each cluster. This variable therefore represents access to clean environmental conditions at the community level, affected by both household resources and the broader communitylevel infrastructure (e.g. waste disposal infrastructure and distance to water source or electricity grid).

\section{Statistical analysis}

Analysis of variance (ANOVA) was used to assess the bivariate association between average WAZ and HAZ and selected independent variables, including child sex and age, maternal education, MHSB, economic status (the latter two recoded into 5-level variables using the quintile 
Table 2: Distribution (\%) of variables

\begin{tabular}{|c|c|c|c|c|c|}
\hline Variables & 1991 & 1998 & Variables & 1991 & 1998 \\
\hline $\mathbf{N}$ & 1587 & 1923 & & 1587 & 1923 \\
\hline Level I variables & & & Level I variables (cont'd) & & \\
\hline Child characteristics & & & Economic status (ES) & & \\
\hline Sex & & & Ist quintile & 16.5 & 22.6 \\
\hline Male & 49.4 & 50.0 & $2^{\text {nd }}$ quintile & 15.7 & 23.0 \\
\hline Female & 50.6 & 50.0 & $3^{\text {rd }}$ quintile & 22.6 & 18.0 \\
\hline Age (months) & & & $4^{\text {th }}$ quintile & 20.3 & 19.5 \\
\hline $0-5$ & 17.7 & 19.0 & $5^{\text {th }}$ quintile & 24.9 & 16.9 \\
\hline $6-11$ & 21.1 & 17.7 & Continuous (Mean) & -0.82 & -0.99 \\
\hline $12-23$ & 34.6 & 33.9 & MHSB & & \\
\hline $24-35$ & 26.6 & 29.4 & |st quintile & 14.8 & 20.6 \\
\hline Breastfeeding duration & & & $2^{\text {nd }}$ quintile & 18.3 & 21.9 \\
\hline Never breastfed & 0.9 & 0.7 & $3^{\text {rd }}$ quintile & 19.5 & 21.3 \\
\hline Still breastfeeding & 56.7 & 58.9 & $4^{\text {th }}$ quintile & 20.1 & 20.8 \\
\hline Breastfed $0-4$ months & 1.9 & 0.9 & $5^{\text {th }}$ quintile & 27.3 & 15.4 \\
\hline Breastfed 5-6 months & 1.6 & 0.8 & Continuous (Mean) & 0.89 & 0.68 \\
\hline Breastfed 7-18 months & 28.5 & 25.8 & Household environment & & \\
\hline Breastfed 19 months or more & 10.4 & 12.6 & Water & & \\
\hline Missing & 0.0 & 0.2 & Poor $=$ Well, rain, river & 61.2 & 64.7 \\
\hline Preceding birth interval & & & Medium = Public tap & 20.2 & 17.8 \\
\hline First born child & 18.6 & 22.0 & Good = Piped water & 18.4 & 11.2 \\
\hline $7-18$ months & 6.4 & 4.7 & Missing & 0.2 & 6.2 \\
\hline 19-23 months & 7.8 & 8.6 & Sanitation & & \\
\hline 24 months or more & 67.2 & 64.7 & Poor $=$ Pit latrine & 55.3 & 69.6 \\
\hline Birth size & & & Medium $=$ Bucket or improved pit latrine & 7.3 & 4.0 \\
\hline Smaller than average & 15.6 & 10.8 & Good = Flush toilet & 37.3 & 20.4 \\
\hline Average & 54.6 & 52.0 & Missing & 0.1 & 6.0 \\
\hline Larger than average & 29.8 & 37.2 & Cooking fuel & & \\
\hline Maternal characteristics & & & Poor $=$ No electric stove or portable gas & 78.9 & 73.1 \\
\hline Education & & & Good = Electric stove, portable gas & 20.9 & 20.9 \\
\hline No education & 34.7 & 33.5 & Missing & 0.2 & 6.0 \\
\hline Primary & 41.8 & 40.2 & & & \\
\hline Secondary or + & 23.5 & 26.3 & Level 2 variables & & \\
\hline Maternal age at birth (yrs) & & & Place of residence & & \\
\hline$<20$ & 22.8 & 21.1 & Yaounde/Douala & 14.0 & 7.7 \\
\hline 20-29 & 51.3 & 52.5 & Intermediate cities & 25.7 & 18.7 \\
\hline $30-49$ & 25.8 & 26.4 & Rural & 60.3 & 73.6 \\
\hline Marital status & & & Region of residence & & \\
\hline Married monogamy & 51.4 & 52.2 & Yaounde/Douala & 14.0 & 7.7 \\
\hline Other & 48.6 & 47.8 & West/Littoral & 17.6 & 12.5 \\
\hline Household characteristics & & & North-West/South-West & 15.8 & 17.6 \\
\hline Indicators for ES (\% yes) & & & Center/South/East & 20.7 & 24.5 \\
\hline Radio & 66.1 & 52.6 & Adamaoua/North/Far-North & 31.9 & 37.7 \\
\hline Electricity & 35.3 & 34.2 & Community environmental status (Mean) & -0.46 & -0.75 \\
\hline Television & 22.8 & 18.3 & & & \\
\hline Car & 7.9 & 4.7 & & & \\
\hline \multicolumn{6}{|l|}{ Indicators for MHSB (\% yes) } \\
\hline Prenatal attendance & 83.9 & 79.5 & & & \\
\hline Tetanus injection during pregnancy & 76.5 & 70.4 & & & \\
\hline Medical assistance at delivery & 68.0 & 59.0 & & & \\
\hline Knowledge of ORS & 42.4 & 56.6 & & & \\
\hline
\end{tabular}

ABBREVIATIONS: $E S$ = household economic status; $M H S B=$ maternal health-seeking behavior

Notes: The ES and MHSB quintiles were constructed using pooled I99I and I998 DHS data to facilitate cross-year comparability. Higher proportion of children in the $\mathrm{I}^{\mathrm{st}}$ and $2^{\text {nd }} \mathrm{ES}$ and MHSB quintile in 1998 compared with $199 \mathrm{I}$ indicates declines in ES and MHSB during the 1990s, as confirmed by change in the mean value of these variables between the two periods; these changes were statistically significant at $0.00 \mathrm{I}$. Also note that ES and MHSB "indicators" were not included as independent variables in multivariate analyses. 
Table 3: Nutritional status in Cameroon in 1991 and 1998

\begin{tabular}{|c|c|c|c|}
\hline & 1991 & 1998 & P-value of change \\
\hline & \multicolumn{3}{|c|}{ Crude estimates } \\
\hline WAZ & -0.70 & -0.83 & 0.006 \\
\hline HAZ & -1.03 & -1.14 & 0.026 \\
\hline WHZ & -0.09 & -0.16 & 0.069 \\
\hline$\% W A Z<-2$ SD & 16.3 & 22.2 & $<0.0001$ \\
\hline \% HAZ<-2 SD & 22.9 & 29.3 & $<0.0001$ \\
\hline \multirow[t]{2}{*}{$\% \mathrm{WHZ}<-2 \mathrm{SD}$} & 3.8 & 5.9 & 0.004 \\
\hline & \multicolumn{3}{|c|}{ Standardized estimates $\mid$} \\
\hline WAZ & -0.70 & -0.79 & 0.042 \\
\hline HAZ & -1.03 & -1.08 & 0.239 \\
\hline WHZ & -0.09 & -0.15 & 0.138 \\
\hline$\% W A Z<-2$ SD & 16.3 & 20.6 & $<0.0001$ \\
\hline \% HAZ<-2 SD & 22.8 & 27.3 & 0.002 \\
\hline$\% \mathrm{WHZ}<-2 \mathrm{SD}$ & 3.8 & 6.0 & 0.004 \\
\hline
\end{tabular}

-ABBREVIATIONS: WAZ: weight-for-age z-score; HAZ: height-forage z-score; WHZ: weight-for-age z-score; \% WAZ<-2 SD: percentage of children with weight-for-age $z$-score 2 standard deviations (SD) below the median value of weight-for-age z-score of the international reference population; the same definition applies to $\% H A Z<-2 S D$ and \%WHZ<-2SD by replacing WAZ by HAZ and WHZ, respectively. I The 1998 estimates were standardized by urban/ rural place of residence and child sex and age; they measure child nutritional status in 1998 if the distributions of study population across urban and rural areas and across child sex and age in 1998 were similar to the 1991 distributions.

cut-off points of the pooled 1991 and 1998 data), water, sanitation, cooking fuel, and place and region of residence. A two tailed t-test was also performed to test the statistical significance of the change in the average WAZ and HAZ between 1991 and 1998 (table 4).

In multivariate analysis, we pooled the 1991 and 1998 data and used a two-level random intercept model to estimate the specific effect of household and community independent variables on WAZ and HAZ, using the Stata 9 statistical software. This model takes into account the hierarchical sample selection design characterizing the DHS surveys, and further adjusts for spatial correlation and heteroskedasticity, as the nutritional status of children living in the same neighborhoods (hereafter 'cluster') may be correlated due to common neighborhoods influences (e.g. access to water, electricity, etc.) This model also allows estimation of the fraction of variance of the dependent variable occurring at each level of the analysis $[31,32]$, and is specified (for WAZ) as follows.

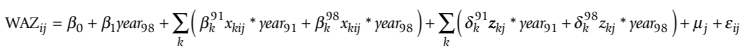

where

$\mathrm{WAZ}_{i j}=$ weight-for-age $\mathrm{z}$-score for a child $i$ in cluster $j$ $\beta_{0}=$ intercept

year $_{t}=$ dummy indicator for the year $t(t=1991,1998)$

$\beta_{1}=$ coefficient on the year 1998

$x_{k i j}=$ value of variable $x_{k}$ for a child $i$ in cluster $j\left(x_{k}\right.$ is an individual or household level variable)

$x_{k i j}{ }^{*}$ year $_{t}=$ interaction term between variable $x_{k}$ and year $t$ $(t=1991,1998)$ evaluated for a child $i$ in cluster $j$

$\beta_{k}^{t}=$ coefficient on variable $x_{k}$ in period $t(t=1991,1998)$, representing increase in WAZ due to a unit increase in $x_{k}$ if $x_{k}$ is continuous, or the differential effect of $x_{k}$ on WAZ relative to a reference category if $x_{k}$ is a dummy indicator representing a category of a categorical variable

$z_{k j}=$ value of variable $z_{k}$ for a cluster $j\left(z_{k}\right.$ is a community level variable)

$z_{k j} *$ year $_{t}=$ interaction term between variable $z_{k}$ and year $t$ $(t=1991,1998)$ evaluated for a cluster $j$

$\delta_{k}^{t}=$ coefficient on variable $z_{k}$ in period $t(t=1991,1998)$,

interpreted similarly as $\beta_{k}^{t}$

$\mu_{j}=$ clusters residuals assumed to be independent and normally distributed

$\varepsilon_{i j}=$ within-cluster individuals residuals assumed to be independent and normally distributed.

The residual terms $\mu_{j}$ and $\varepsilon_{i j}$ are assumed to have zero mean, with respective variances $\sigma_{\mu}^{2}$ and $\sigma_{\varepsilon}^{2}$, which are the variance of WAZ occurring at the cluster and individual level, respectively, after netting out the effects of independent variables. Only coefficients $\beta_{k}^{91}$ and $\beta_{k}^{98}$ estimating simultaneously the effects of these independent variables for the years 1991 and 1998, respectively, were reported in addition to the individual and cluster level variances $\sigma_{\varepsilon}^{2}$ and $\sigma_{\mu}^{2}$ (table 5).

To estimate changes across years in the effects of independent variables, we used the following equation:

$\mathrm{WAZ}_{i j}=\alpha_{0}+\alpha_{1}$ year $_{98}+\sum_{k}\left(\alpha_{k}^{98-91} x_{k i j}{ }^{*}\right.$ year $\left._{98}+\alpha_{k}^{91} x_{k i j}\right)+\sum_{k}\left(\varphi_{k}^{98-91} z_{k j}{ }^{*}\right.$ year $\left._{98}+\varphi_{k}^{91} z_{k j}\right)+\mu_{j}+\varepsilon_{i j}$ 
Table 4: Average weight-for-age and height-for-age for selected variables

\begin{tabular}{|c|c|c|c|c|c|c|}
\hline & \multicolumn{3}{|c|}{ Weight-for-age z-score } & \multicolumn{3}{|c|}{ Height-for-age z-score } \\
\hline & 1991 & 1998 & Change & 1991 & 1998 & Change \\
\hline \multicolumn{7}{|l|}{ Household Economic status } \\
\hline Ist quintile & -1.03 & -1.20 & -0.17 & -1.26 & -1.47 & -0.21 \\
\hline $2^{\text {nd }}$ quintile & -0.71 & -0.91 & -0.20 & -1.02 & -1.16 & -0.14 \\
\hline $3^{\text {rd }}$ quintile & -0.94 & -0.96 & -0.02 & -1.35 & -1.27 & 0.08 \\
\hline $4^{\text {th }}$ quintile & -0.51 & -0.62 & -0.11 & -0.95 & -0.97 & -0.02 \\
\hline $5^{\text {th }}$ quintile & -0.42 & -0.35 & 0.07 & -0.68 & -0.75 & -0.07 \\
\hline \multicolumn{7}{|l|}{ MHSB } \\
\hline I st quintile & -1.31 & -1.34 & -0.03 & -1.38 & -1.54 & -0.16 \\
\hline $2^{\text {nd }}$ quintile & -0.83 & -0.92 & -0.09 & -1.05 & -1.12 & -0.07 \\
\hline $3^{\text {rd }}$ quintile & -0.66 & -0.76 & -0.10 & -1.11 & -1.22 & -0.11 \\
\hline $4^{\text {th }}$ quintile & -0.64 & -0.58 & 0.06 & -0.94 & -0.92 & 0.02 \\
\hline $5^{\text {th }}$ quintile & -0.36 & -0.47 & -0.11 & -0.84 & -0.84 & 0 \\
\hline \multicolumn{7}{|l|}{ Household environment } \\
\hline \multicolumn{7}{|l|}{ Water } \\
\hline Poor & -0.88 & -0.94 & -0.06 & -1.20 & -1.23 & -0.03 \\
\hline Medium & -0.56 & -0.71 & -0.15 & -0.91 & -1.01 & -0.10 \\
\hline Good & -0.24 & -0.38 & -0.14 & -0.60 & -0.84 & $-0.24 * *$ \\
\hline \multicolumn{7}{|l|}{ Sanitation } \\
\hline Poor & -0.88 & -0.94 & -0.06 & -1.20 & -1.24 & -0.04 \\
\hline Medium & -0.39 & -0.13 & 0.26 & -0.68 & -0.51 & 0.17 \\
\hline Good & -0.50 & -0.58 & -0.08 & -0.84 & -0.90 & -0.06 \\
\hline \multicolumn{7}{|l|}{ Cooking fuel } \\
\hline Poor & -0.25 & -0.55 & $-0.30 *$ & -0.82 & -0.88 & -0.06 \\
\hline Good & -0.82 & -0.94 & $-0.12^{* *}$ & -1.15 & -1.24 & $-0.09 * *$ \\
\hline \multicolumn{7}{|l|}{ Maternal education } \\
\hline No education & -1.08 & -1.35 & $-0.27^{* *}$ & -1.28 & -1.48 & -0.20 \\
\hline Primary & -0.57 & -0.65 & -0.08 & -1.01 & -1.06 & -0.05 \\
\hline Secondary or + & -0.38 & -0.45 & -0.07 & -0.71 & -0.84 & -0.13 \\
\hline \multicolumn{7}{|l|}{ Child sex } \\
\hline Male & -0.71 & -0.91 & $-0.20 * *$ & -1.03 & -1.21 & $-0.18^{* *}$ \\
\hline Female & -0.70 & -0.76 & -0.06 & -1.04 & -1.08 & -0.04 \\
\hline \multicolumn{7}{|l|}{ Child age (months) } \\
\hline $0-5$ & 0.43 & 0.45 & 0.02 & -0.02 & -0.07 & -0.05 \\
\hline $6-11$ & -0.65 & -0.80 & -0.15 & -0.75 & -0.64 & 0.11 \\
\hline $12-23$ & -1.16 & -1.35 & $-0.19 * *$ & -1.42 & -1.69 & $-0.27 * *$ \\
\hline $24-35$ & -0.91 & -1.09 & $-0.18^{* *}$ & -1.43 & -1.51 & -0.08 \\
\hline \multicolumn{7}{|l|}{ Place of residence } \\
\hline Yaounde/Douala & -0.16 & -0.31 & -0.15 & -0.57 & -0.75 & -0.18 \\
\hline Intermediate cities & -0.71 & -0.73 & -0.02 & -1.00 & -1.01 & -0.01 \\
\hline Rural (reference) & -0.82 & -0.91 & -0.09 & -1.15 & -1.22 & -0.07 \\
\hline \multicolumn{7}{|l|}{ Region } \\
\hline West/Littoral & -0.35 & -0.37 & -0.02 & -0.96 & -0.96 & 0.0 \\
\hline North-West/South-West & -0.45 & -0.44 & 0.01 & -1.10 & -0.94 & 0.16 \\
\hline Center/South/East & -0.83 & -0.82 & 0.01 & -1.01 & -1.12 & -0.11 \\
\hline Adamaoua/North/Far-North & -1.17 & -1.29 & -0.12 & -1.25 & -1.40 & -0.15 \\
\hline
\end{tabular}

-Statistical significance of change: *: $\mathrm{P}<0.10 ; * *$ : $<<0.05 ; * * *$ : $<<0.001$

-Gradient in weight-for-age and height for age z-scores for each independent variable shown in the table was statistically significant at $0.00 \mathrm{I}$.

Note that equation (2) is algebraically equivalent to equation (1) in that $\alpha_{k}^{91}=\beta_{k}^{91}$, $\varphi_{k}^{91}=\delta_{k}^{91}, \alpha_{k}^{98-91}=\beta_{k}^{98}-\beta_{k}^{91}$ and $\varphi_{k}^{98-91}=\delta_{k}^{98}-\delta_{k}^{91}$. Therefore only coefficients $\alpha_{k}^{98-91}$ and $\varphi_{k}^{98-91}$ estimating respectively the cross-year changes in the effects of individual/household and community independent variables were reported (table 7). Equation (1) and equation (2) were also estimated for height-for-age z-score by replacing WAZ by HAZ (tables 6-7).

Summarizing what precedes, while equation (1) estimates the effects of independent variables for the years 1991 and 
1998 simultaneously, equation (2) estimates changes in the effects of these variables between the two years.

The testing strategy used in the multivariate analysis estimated first the effects of some socioeconomic factors (tables 5-6, models 1-2) and environmental factors (tables 5-6, model 3) on nutritional status in separate equations; because maternal education and place of residence were used as predictors in the construction of economic status and MHSB, the adjusted effects of these variables were estimated separately (tables 5-6, models 4-6). We also estimated the full model including all independent variables (tables 5-6, model 7). Finally, we estimated the age-specific effects of household economic status to check variations in these effects by child age (table 8). Multilevel analyses were not weighted.

\section{Results}

\section{Descriptive and bivariate analysis}

Average WAZ and HAZ in children younger than 3 years old in Cameroon declined respectively from -0.70 standard deviations (SD), i.e. 0.70 SD below the reference median value, to -0.83 SD $(\mathrm{p}=0.006)$, and from -1.03 SD to -1.14 SD ( $p=0.026)$ between 1991 and 1998. During this period, the prevalence of underweight (defined as $\mathrm{WAZ}<-2 \mathrm{SD})$ and stunting (\% $\mathrm{HAZ}<-2 \mathrm{SD})$ increased respectively from $16 \%$ to $22 \%(\mathrm{P}<0.0001)$, and from
$23 \%$ to $29 \%$ ( $\mathrm{p}<0.0001$ ). Average weight-for-height $\mathrm{z}$ score (WHZ) also deteriorated, mirroring increase in the prevalence of wasting (\%WHZ<-2 SD) (table 3). Because of a shift of the sample toward rural children during this period (see tables 1 and 2), trends in nutritional indicators were adjusted for place of residence and child sex and age, and we still found evidence of a decline in nutritional status. It should be noted that this sample shift might reflect a massive urban-to-rural migration flow during the 1990s economic crisis [33-35], in addition to a lower fertility decline in rural areas compared to urban areas during this period $[36,37]$.

Results for bivariate analyses are presented in table 4 . The decline in nutritional status occurred mostly in boys, children aged 12-23 months, those born to uneducated mothers, and those of low economic status. Child sex was not significantly associated with nutritional status in 1991, but girls had higher average WAZ and HAZ compared to boys in 1998 due to uneven declines. Child age was also a significant predictor of nutritional status.

In both years, nutritional status improved with maternal education (table 4, figures 1a-b). Further, the advantage associated with education increased between 1991 and 1998, as decline in WAZ and HAZ was concentrated in children of uneducated mothers, although this advantage
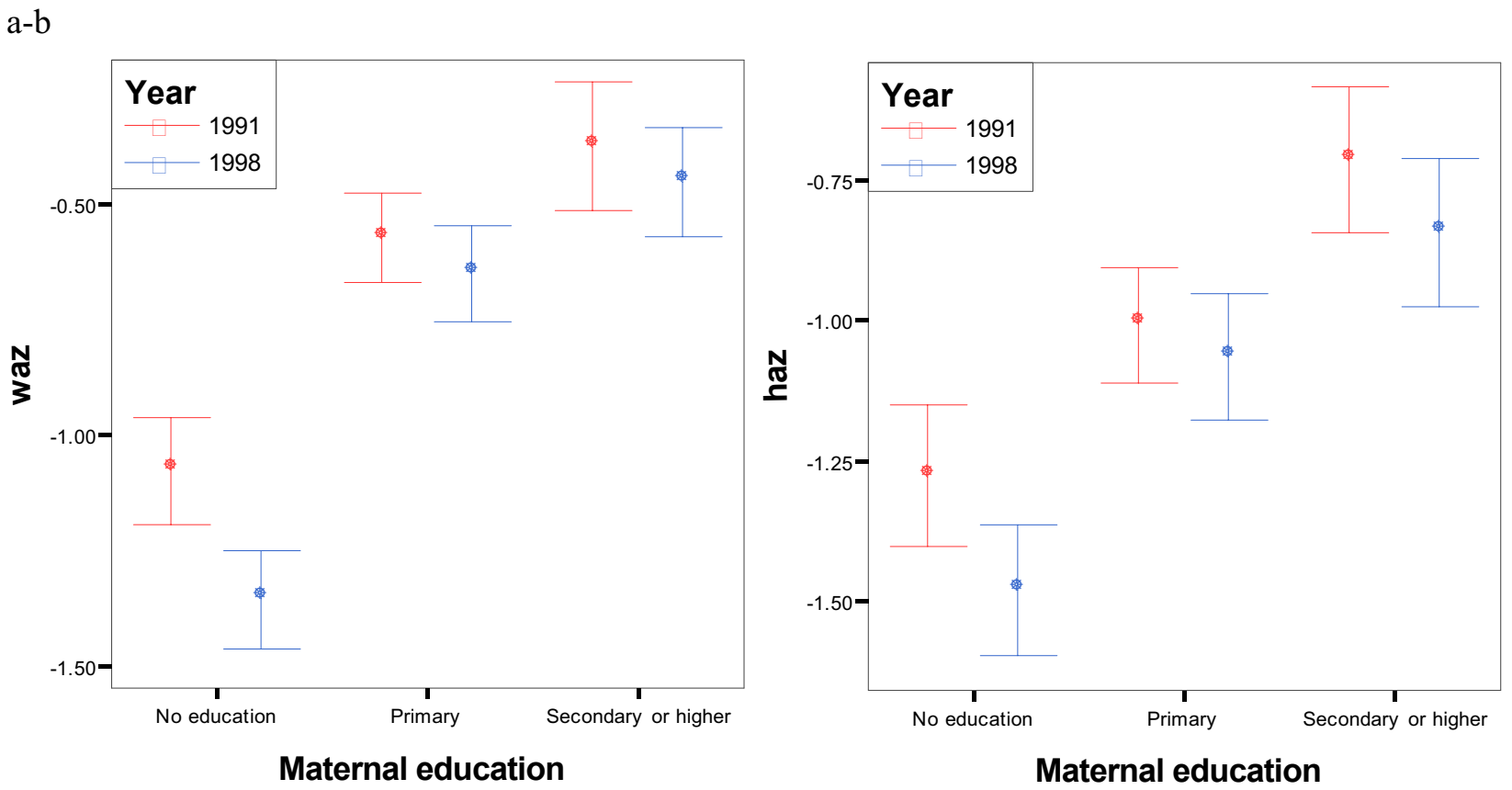

Figure Ia-b

Educational gradient in weight-for-age (WAZ) and height-for-age z-scores (HAZ) in I99I and I998 in Cameroon. error bars represent $95 \% \mathrm{Cl}$ around the mean. 
was not statistically significant when clustering of observations was taken into account (see unadjusted model in table 7). A positive economic status gradient was also noted in 1991 and 1998 (table 4, figures 2a-b). Moreover, the gap between the richest and the poorest economic groups increased during this period, although not significantly. Maternal health seeking behavior also had a significantly positive effect on nutritional status in both years (table 4, figures 3a-b). Further, the difference in HAZ between children born to mothers with the highest MHSB and those born to mothers with the lowest MHSB increased during the crisis, but not significantly.

Improved water and cleaner cooking fuels were also associated with better nutritional status in 1991 and 1998 (table 4; also see figures $4 \mathrm{a}-\mathrm{b}$ for water). Similar results were found for sanitation. Children with flush toilets in their houses had lower nutritional status than those with improved pit latrines, but this anomaly was not statistically significant.

At the community level, child nutritional status was higher in urban areas in each year (table 4). Average WAZ was -0.16 SD in the largest cities Yaounde and Douala and $-0.82 \mathrm{SD}$ in rural areas in $1991(\mathrm{p}<0.001)$; it was respectively -0.31 SD and -0.91 SD in $1998(\mathrm{p}<0.001)$. Average HAZ was -0.57 SD in Yaounde/Douala and -1.15 SD in rural areas in 1991 ( $\mathrm{p}<0.001)$, and was respectively -0.75 SD and -1.22 SD in 1998 ( $p<0.001)$. In both years, the advantage of children in intermediate cities versus rural areas was not statistically significant for either nutritional indicator. Significant regional variation in child nutrition was also observed in the country (table 4; also see figures $5 a-b)$. Children living in the West or Littoral province had the highest nutritional status after those living in the largest cities; in contrast, children in northern Cameroon had the lowest average WAZ and HAZ.

\section{Multivariate results}

Effects of socioeconomic and environmental factors

The multivariate, multilevel linear regression confirmed many of the results found in bivariate analyses, but the effects of some variables declined. Controlling for economic status and MHSB showed positive effects of these variables on WAZ (table 5, model 1) and HAZ (table 6, model 1); however, the effect of MHSB completely disappeared in 1998 after additional control for maternal education, while remaining significantly positive in 1991 (table 5-6, model 2). Maternal education had a positive effect in both years. Model 3 shows positive effects of water, sanitation and cooking fuel, but some of these effects diminished in favor of community environmental status after additional control for this variable (model not shown).

$a-b$
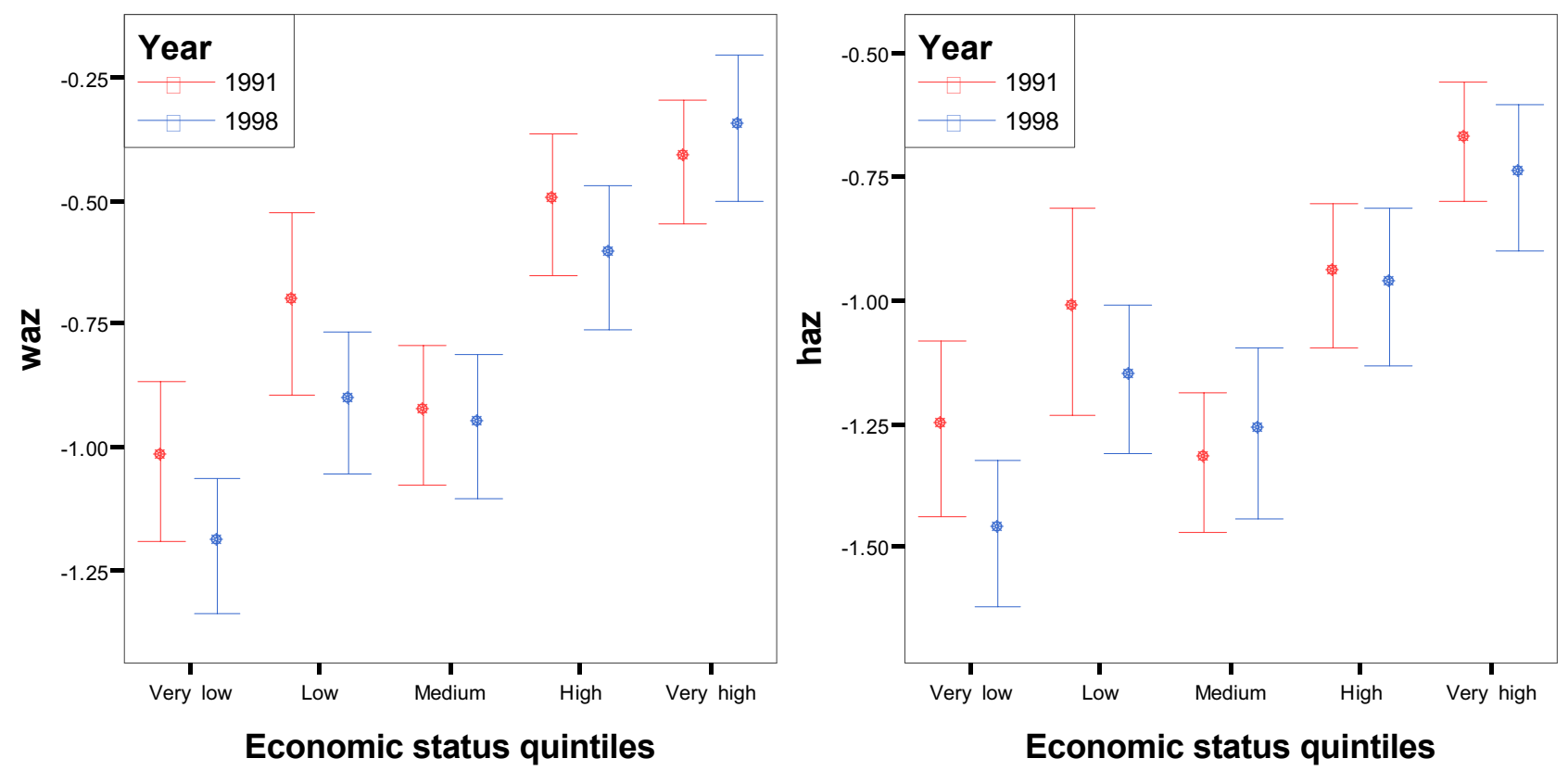

Figure 2a-b

Effect of household economic status on WAZ and HAZ. error bars represent $95 \% \mathrm{Cl}$ around the mean. 
Because maternal education and place of residence were used as predictors in the construction of economic status and MHSB, and because of the high correlation of economic status with community environmental status $\left(\mathrm{R}^{2}=\right.$ 0.74 in each year), showing that poorer households most often live in unclean neighborhoods, we estimated the effects of these variables in separate regressions after adjusting for all other variables. The effects of economic status and MHSB were still positive (tables 5-6, model 4), but the effect of economic status diminished in 1991 in favor of water, sanitation and cooking fuel after additional adjustment for these variables (tables 5-6, model $5)$. Also, maternal education and community environmental status still have positive effects (tables 5-6, model 6).

The full model (model 7) did not significantly change the effects of our main exposures on WAZ and HAZ. We note that either economic status or household or community environmental variables became non-significant, showing that environmental conditions are systematic modulators of the income-nutrition relationship. We also note that in general, either maternal education or MHSB became non-significant, thus highlighting the positive correlation of education with better use of primary health care facilities, and their joint positive impact on child nutrition.

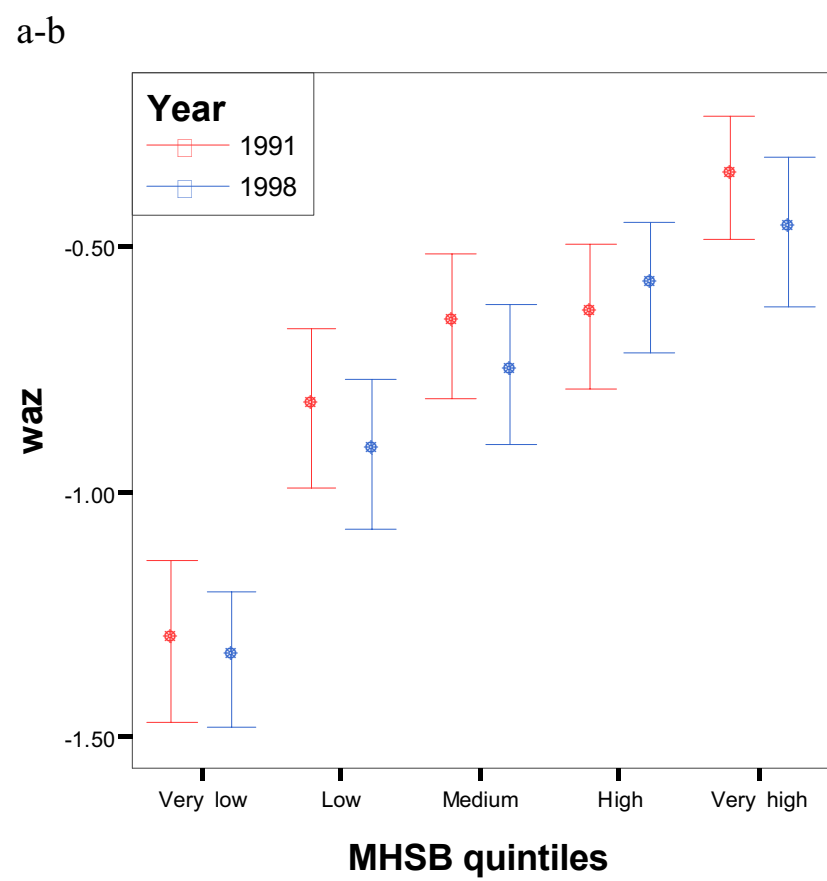

The full model also showed that children living in the largest cities were still better off than those in rural areas (this is true for WAZ in both years and for HAZ in 1998), but those in the intermediate cities were eventually worse off as compared with rural areas (this is true for WAZ). This implies that the relative advantage associated with the intermediate cities over the rural areas was entirely due to the socioeconomic composition of those milieus. Regional differentials in child nutritional status remained robust to all controls for WAZ, and the relative advantage of some southern regions over the northern region increased over time, although not significantly.

Changes in the effects of independent variables during the crisis We estimated changes over time in the effects of independent variables (table 7). The full model including all independent variables was first used for this purpose, but to avoid possible bias due to correlation between some variables as previously discussed, model 5 was used for all variables except for maternal education, place and region of residence, and community environmental index which were estimated from model 6 . However the results of this exercise were very similar. We note that the positive effect of economic status (significant for WAZ and non-significant for HAZ) increased during the crisis, while the effects of environmental variables diminished in general. Maternal education also had a non-significant increasing effect

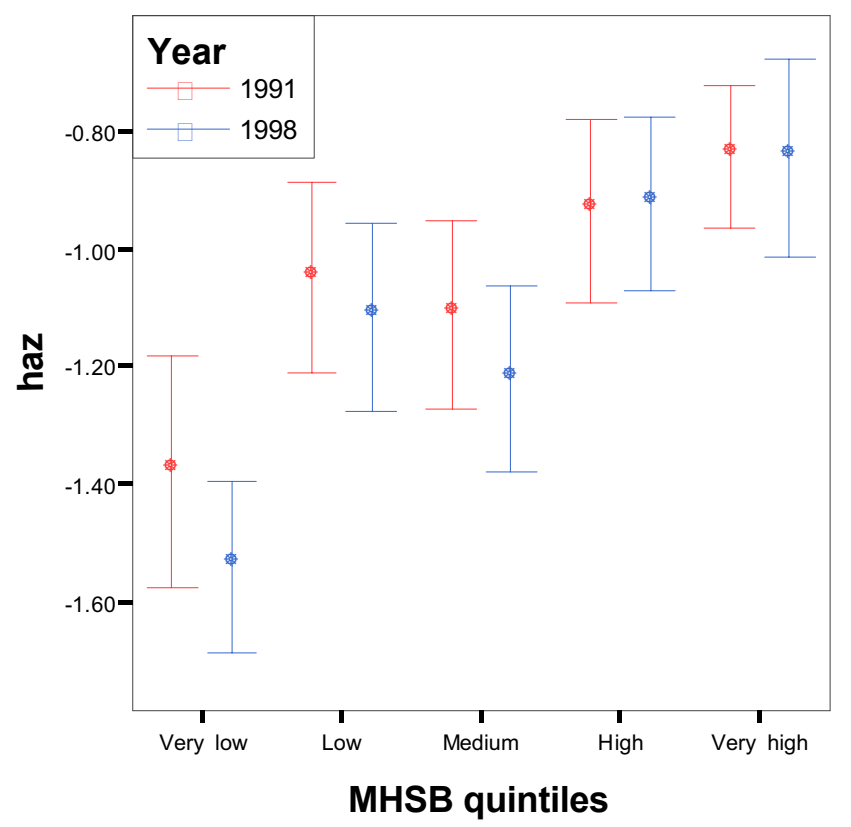

Figure 3a-b

Effect of MHSB on WAZ and HAZ. error bars represent $95 \% \mathrm{Cl}$ around the mean. 
during this period. The relative advantage of girls over boys also increased over time, while the advantage of living monogamously diminished, perhaps suggesting that the crisis had a greater impact on stable families.

\section{Age-specific effects of household economic status}

We estimated variation across child age groups in the nutritional effects of household economic status (table 8). We note that this variable had little effect in children under 6 months of age, but its effect was positive on length-for-age in that age group in 1998. The effect of economic status was in general significantly greater in children above 6 months, compared to younger children. This result suggests that children under 6 months of age should be distinguished from older children in the analysis of factors associated with child nutrition outcomes.

\section{Discussion}

We examined the household and community level socioeconomic and environmental factors associated with nutritional status among children under 3 years old in Cameroon and assessed the changes in the effects of those factors between 1991 and 1998, which was a period of severe economic crisis in the country. Real GDP per capita fell from I\$ 2266 in 1990 to I\$ 1949 in 1998 (1996 constant price) [38]. Average weight-for-age z-score and height-for-age $\mathrm{z}$-score declined respectively from -0.70 SD to -0.83 SD $(\mathrm{p}=0.006)$ and from -1.03 SD to -1.14 SD ( $p$
$=0.026$ ) during this period. The situation experienced in Cameroon during this period was opposite to global trends in malnutrition [5,39]. The prevalence of stunting declined in Africa, Asia, Latin America and the Caribbean during the 1990s, but remained stable in Western and Eastern Africa, as well as Central America. Downward trends in malnutrition were also noted in Indonesia despite the 1997/1998 financial crisis [12,40]. Growth experienced by many developing countries was followed by nutrition transition, often implying a rising pattern of obesity $[6,41]$ or a double burden of malnutrition and obesity in some households [42].

The positive effect of maternal education and health seeking behavior on child nutritional status found in our study is consistent with other studies on factors affecting child health, such as those in India and Mali $[43,44]$.

Economic status had a positive effect in general, but it had little effect in children aged 0-5 months, and had significantly positive effect in older ages. It is possible that the little effect of economic status in 0-5 months is due to the role of breastfeeding, which is less frequent in high-economic status mothers than lower economic status mothers due to time budget and the ability to pay for supplementation foods. The effect of economic status in children aged 0-5 months increased between 1991 and 1998 (this is particularly true for HAZ where it was posi-

$\mathrm{a}-\mathrm{b}$
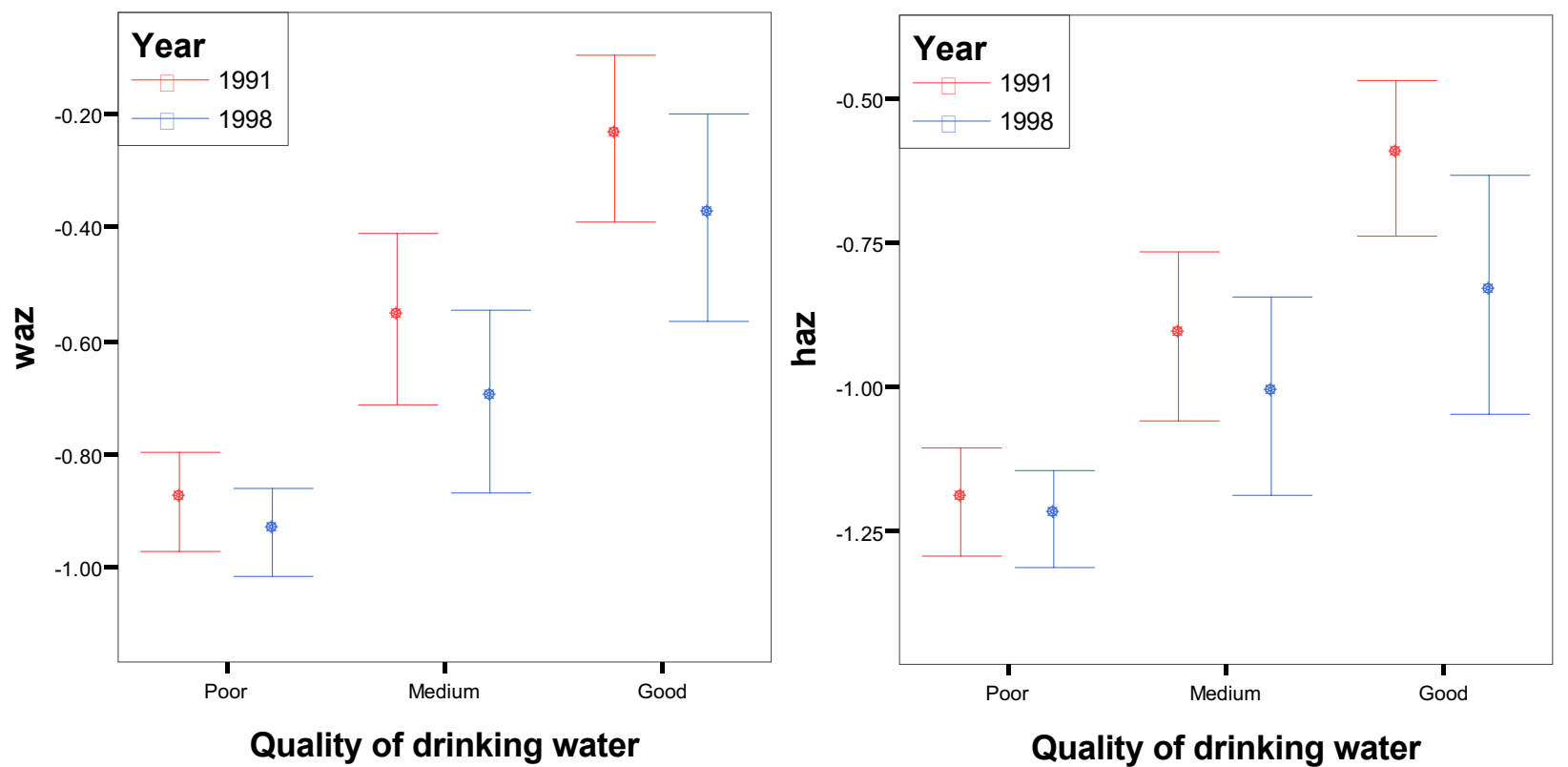

Figure 4a-b

Variation in WAZ and HAZ by quality of drinking water. error bars represent $95 \% \mathrm{Cl}$ around the mean. 
tive in 1998), however, perhaps reflecting the high sensitization toward breastfeeding during the 1990s, shifting even high-economic status mothers to frequently breastfeeding their children. Unavailability of adequate data on quality of breastfeeding did not allow us to test this hypothesis. When supplementation food becomes important (after the age of 6 months), economic status is associated with improved child nutritional status because of the relative facility of high economic status mothers to afford supplementation. The age-specific effect of economic status found in our study is consistent with Sahn et al. [17], although this study used more aggregated age groups.

The positive nutritional effect of improved water and sanitation found in this study is consistent with other studies conducted in developing countries [11,45]. Unclean water may affect nutritional status through diarrhoeal diseases [46-49]. Further, we found that cleaner fuels were associated with better anthropometric indicators, consistent with the only other available study, in South India [43]. The role of clean fuels may be mediated by effects on birth weight [50], or on the risk of respiratory infections $[51,52]$, which may in turn influence growth. Consistently with Fotso et al. [19], we also found that better community environmental status positively affected nutritional status after other factors were adjusted, suggesting that community hygiene affects health irrespectively of individual or household characteristics.

$\mathrm{a}-\mathrm{b}$

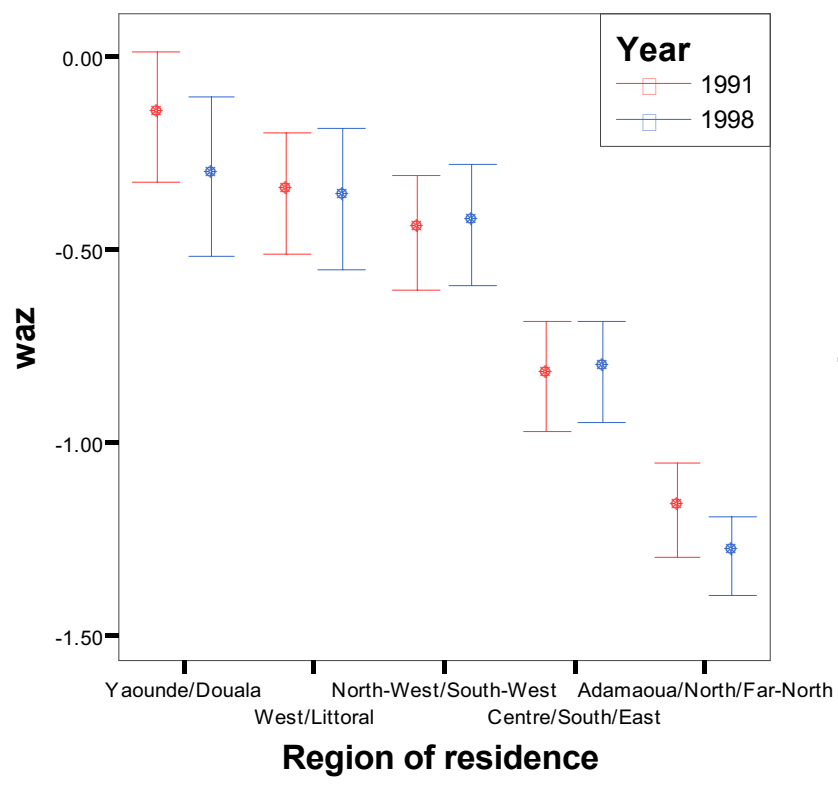

Our study suggests that urban-rural differentials in child nutritional status in Cameroon -especially those between the intermediate cities and rural areas-are mediated by the socioeconomic composition of those areas. The relative advantage of the largest cities over the rural areas declined after all controls, but remained positive (except for HAZ in 1991), which may be attributable to some contextual factors such as better access to and quality of health care in the main cities. This is consistent to some extent with Kuate [53] who found urban advantage in survival of children under 5 years old in Cameroon to be completely mediated by hospital delivery.

Our study also reports regional disparities in child nutritional status that were robust to all controls for WAZ, but that almost disappeared for HAZ, suggesting that much of the regional gap in HAZ is mediated by differential socioeconomic conditions. Northern Cameroon, which is a region with dry climate, limited food crops and limited access to health care, consistently had the worst WAZ. The Center/South/East region had the closest outcome to the North. Such a situation may prevail because of overwhelmingly low access to food and health care in the East province, which should be distinguished from the South and Center provinces which have better access to varied food and health services [53]. Disaggregating analysis to draw this distinction was not possible, due to non-representativeness of sample sizes at the province level.

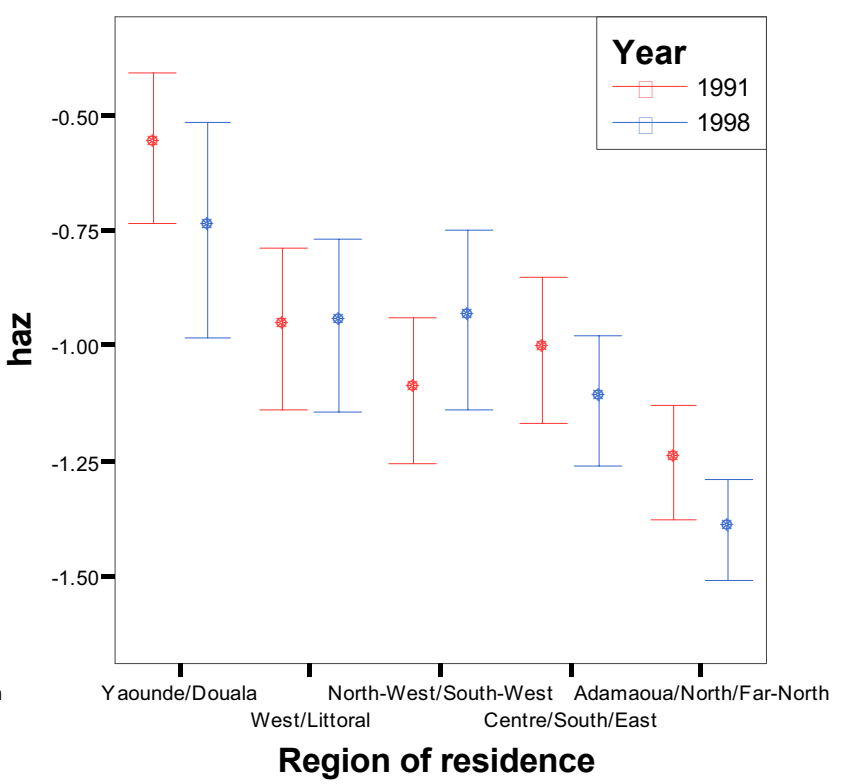

Figure 5a-b

Regional disparities in WAZ and HAZ. error bars represent $95 \% \mathrm{Cl}$ around the mean. 
Table 5: Multilevel linear regression estimates of the effects of socioeconomic and environmental factors on weight-for-age z-score

\begin{tabular}{|c|c|c|c|c|c|c|c|c|c|c|c|c|c|c|}
\hline & \multicolumn{2}{|c|}{ Model I } & \multicolumn{2}{|c|}{ Model 2} & \multicolumn{2}{|c|}{ Model 3} & \multicolumn{2}{|c|}{ Model 4} & \multicolumn{2}{|c|}{ Model 5} & \multicolumn{2}{|c|}{ Model 6} & \multicolumn{2}{|c|}{ Model 7} \\
\hline & 1991 & 1998 & 1991 & 1998 & 1991 & 1998 & 1991 & 1998 & 1991 & 1998 & 1991 & 1998 & 1991 & 1998 \\
\hline \multicolumn{15}{|c|}{ Household Economic status } \\
\hline \multicolumn{15}{|c|}{$\begin{array}{l}\text { Ist quintile } \\
\text { (reference) }\end{array}$} \\
\hline $2^{\text {nd }}$ quintile & 0.184 & 0.174 & 0.191 & 0.140 & & & $0.252^{* *}$ & $0.199 * *$ & $0.232 *$ & $0.222 * *$ & & & $0.233^{*}$ & $0.215^{* *}$ \\
\hline $3^{\text {rd }}$ quintile & -0.125 & 0.129 & -0.116 & 0.121 & & & 0.026 & 0.152 & 0.003 & $0.176 *$ & & & 0.006 & $0.180 *$ \\
\hline $4^{\text {th }}$ quintile & 0.194 & $0.349 * *$ & 0.181 & $0.334 * *$ & & & 0.160 & $0.359 * * *$ & 0.071 & $0.394 * * *$ & & & 0.064 & $0.400 * * *$ \\
\hline $5^{\text {th }}$ quintile & $0.320 * *$ & $0.647 * * *$ & $0.272^{*}$ & $0.638^{* * * *}$ & & & $0.248 *$ & $0.576 * * *$ & 0.049 & $0.575 * * *$ & & & 0.028 & $0.594 * * *$ \\
\hline Continuous & $0.185^{* *}$ & $0.290 * * *$ & $0.162 * *$ & $0.288 * * *$ & & & $0.104 *$ & $0.246 * * *$ & 0.013 & $0.227^{* * *}$ & & & 0.008 & $0.227^{* *}$ \\
\hline \multicolumn{15}{|c|}{ Maternal health-seeking behavior } \\
\hline \multicolumn{15}{|c|}{$\begin{array}{l}\text { Ist quintile } \\
\text { (reference) }\end{array}$} \\
\hline $2^{\text {nd }}$ quintile & $0.352 * *$ & $0.227^{* *}$ & $0.297^{* *}$ & 0.047 & & & 0.120 & -0.050 & 0.121 & -0.038 & & & 0.125 & $-0.07 \mid$ \\
\hline $3^{\text {rd }}$ quintile & $0.438^{* *}$ & $0.24 I^{* *}$ & $0.349 * *$ & -0.087 & & & $0.230 *$ & -0.076 & $0.236 *$ & -0.071 & & & $0.229 *$ & -0.143 \\
\hline $4^{\text {th }}$ quintile & $0.455^{* *}$ & $0.331 * *$ & $0.293 *$ & -0.074 & & & 0.203 & 0.023 & 0.187 & 0.036 & & & 0.173 & -0.059 \\
\hline $5^{\text {th }}$ quintile & $0.647^{* * *}$ & $0.359 * *$ & $0.440^{* *}$ & -0.152 & & & $0.355^{* *}$ & 0.047 & $0.308 * *$ & 0.036 & & & $0.279 *$ & -0.079 \\
\hline Continuous & $0.193 * * *$ & $0.128 * *$ & $0.125^{* *}$ & -0.426 & & & $0.137^{* *}$ & 0.043 & $0.110^{* *}$ & 0.042 & & & $0.112 * *$ & 0.004 \\
\hline \multicolumn{15}{|c|}{ Household environment } \\
\hline \multicolumn{15}{|c|}{ Water } \\
\hline Poor (reference) & & & & & & & & & & & & & & \\
\hline Medium & & & & & 0.167 & $0.157^{*}$ & & & 0.040 & -0.046 & & & 0.006 & -0.030 \\
\hline Good & & & & & $0.470^{* * * *}$ & $0.209 *$ & & & $0.278 * *$ & -0.034 & & & $0.234^{* *}$ & -0.023 \\
\hline Sanitation & & & & & & & & & & & & & & \\
\hline Poor (reference) & & & & & & & & & & & & & & \\
\hline Medium & & & & & 0.031 & $0.361^{* *}$ & & & -0.098 & 0.212 & & & -0.147 & 0.195 \\
\hline Good & & & & & 0.093 & 0.088 & & & 0.052 & -0.117 & & & 0.042 & -0.113 \\
\hline Cooking fuel & & & & & & & & & & & & & & \\
\hline Poor (reference) & & & & & & & & & & & & & & \\
\hline Good & & & & & $0.312 * *$ & $0.240 * *$ & & & $0.218 * *$ & 0.091 & & & 0.188 & 0.087 \\
\hline Maternal educat & & & & & & & & & & & & & & \\
\hline $\begin{array}{l}\text { No education } \\
\text { (reference) }\end{array}$ & & & & & & & & & & & & & & \\
\hline Primary & & & $0.262^{* *}$ & $0.595 * * *$ & & & & & & & 0.133 & $0.300 * *$ & 0.055 & $0.287^{* *}$ \\
\hline Secondary or + & & & $0.399 * *$ & $0.732 * * *$ & & & & & & & $0.213^{*}$ & $0.406 * * *$ & 0.091 & $0.319 * *$ \\
\hline Maternal age at & irth (yrs) & & & & & & & & & & & & & \\
\hline$<20$ (reference) & & & & & & & & & & & & & & \\
\hline $20-29$ & & & & & & & 0.032 & 0.079 & 0.026 & 0.084 & 0.019 & 0.104 & 0.026 & 0.094 \\
\hline $30-49$ & & & & & & & 0.017 & 0.142 & 0.016 & 0.135 & 0.011 & $0.186 *$ & 0.020 & 0.160 \\
\hline Maternal marita & status & & & & & & & & & & & & & \\
\hline Married monogamy & & & & & & & $0.182 * *$ & 0.038 & $0.175 * *$ & 0.028 & $0.186 * *$ & 0.016 & $0.234 * *$ & 0.022 \\
\hline Other (reference) & & & & & & & & & & & & & & \\
\hline Child sex & & & & & & & & & & & & & & \\
\hline Male & & & & & & & -0.074 & $-0.209 * * *$ & -0.067 & $-0.208 * * *$ & -0.072 & $-0.206^{* * *}$ & -0.070 & $-0.207^{* * * *}$ \\
\hline Female (reference) & & & & & & & & & & & & & & \\
\hline Child age (mont & & & & & & & & & & & & & & \\
\hline 0-5 (reference) & & & & & & & & & & & & & & \\
\hline $6-11$ & & & & & & & $-1.121 * * *$ & ${ }^{k}-1.222^{* * * *}$ & $-1.124 * * * ⿰ ㇇ ⿰ 亅 ⿱ 丿 丶 丶$ & $-1.237^{* * *}$ & $-1.114 * * *$ & $-1.210^{* * * *}$ & $-1.126 * * *$ & $-.1 .237 * *$ 冰 \\
\hline $12-23$ & & & & & & & $-1.756 * * *$ & $-1.965 * * *$ & $-1.742 * * *$ & $-1.982 * * *$ & $-1.730 * * *$ & $=-1.949 * * *$ & $=-1.741 * * *$ & $-1.966 * * *$ \\
\hline $24-35$ & & & & & & & $-1.646 * * *$ & $k-1.899 * * *$ & $-1.637 * * * *$ & $-1.913 * * *$ & $-1.617^{* * * *}$ & $-1.869 * * *$ & $=-1.637 * * *$ & $-1.895 * * *$ \\
\hline Birth size & & & & & & & & & & & & & & \\
\hline Small (reference) & & & & & & & & & & & & & & \\
\hline Average & & & & & & & $0.359 * * *$ & $0.188 * *$ & $0.358 * * *$ & $0.178^{* * *}$ & $0.379 * * * *$ & $0.180 * *$ & $0.367^{* * *}$ & $0.175^{* * *}$ \\
\hline Large & & & & & & & $0.797 * * *$ & $0.514^{* * *}$ & $0.796 * * *$ & $0.505^{* * *}$ & $0.814^{* * *}$ & $0.497 * * *$ & $0.799 * * *$ & $0.493^{* * *}$ \\
\hline Breastfeeding du & ation & & & & & & & & & & & & & \\
\hline Never breastfed & & & & & & & -0.240 & -0.205 & -0.232 & -0.110 & -0.186 & -0.207 & -0.209 & -0.102 \\
\hline Still breastfeeding & & & & & & & $-0.559 * *$ & -0.190 & $-0.490 * *$ & -0.128 & $-0.512 * *$ & -0.192 & $-0.466 * *$ & -0.104 \\
\hline $\begin{array}{l}\text { Breastfed 0-4 } \\
\text { months }\end{array}$ & & & & & & & -0.067 & 0.460 & -0.036 & 0.428 & -0.035 & 0.452 & -0.020 & 0.438 \\
\hline $\begin{array}{l}\text { Breastfed 5-6 } \\
\text { months (reference) }\end{array}$ & & & & & & & & & & & & & & \\
\hline Breastfed 7-18 & & & & & & & -0.243 & 0.232 & -0.196 & 0.288 & -0.227 & 0.208 & -0.180 & 0.297 \\
\hline
\end{tabular}


Table 5: Multilevel linear regression estimates of the effects of socioeconomic and environmental factors on weight-for-age z-score

\begin{tabular}{|c|c|c|c|c|c|c|c|c|c|c|c|}
\hline \multicolumn{4}{|l|}{$\begin{array}{l}\text { Breastfed } 19 \\
\text { months or more }\end{array}$} & $-0.534 * *$ & 0.054 & $-0.465^{* *}$ & 0.119 & $-0.503^{* *}$ & 0.061 & $-0.435^{*}$ & 0.152 \\
\hline \multicolumn{12}{|c|}{ Preceding birth interval } \\
\hline \multicolumn{4}{|c|}{ First born child } & -0.002 & 0.023 & -0.008 & 0.034 & -0.029 & 0.005 & -0.009 & 0.0250 \\
\hline \multicolumn{4}{|l|}{$7-18$ months } & -0.088 & $-0.248 *$ & -0.102 & $-0.233^{*}$ & -0.099 & $-0.279 * *$ & -0.102 & $-0.248 *$ \\
\hline \multicolumn{4}{|l|}{ 19-23 months } & -0.182 & -0.864 & -0.161 & -0.089 & -0.164 & -0.089 & -0.158 & -0.096 \\
\hline \multicolumn{12}{|l|}{$\begin{array}{l}24 \text { months or more } \\
\text { (reference) }\end{array}$} \\
\hline \multicolumn{12}{|l|}{ Place of residence } \\
\hline \multicolumn{4}{|l|}{ Yaounde/Douala } & & & & & $0.373 * *$ & $0.366 * *$ & 0.298 & $0.337 *$ \\
\hline \multicolumn{4}{|l|}{ Intermediate cities } & & & & & -0.140 & 0.001 & -0.162 & -0.060 \\
\hline \multicolumn{12}{|l|}{ Rural } \\
\hline \multicolumn{12}{|l|}{ Region } \\
\hline \multicolumn{4}{|l|}{ West/Littoral } & $0.686 * * *$ & $0.778 * * *$ & $0.663 * * *$ & $0.79 \mid * * *$ & $0.601 * * *$ & $0.533 * * *$ & $0.575^{* * * *}$ & $0.618 * * *$ \\
\hline \multicolumn{4}{|l|}{$\begin{array}{l}\text { North-West/South- } \\
\text { West }\end{array}$} & $0.599 * * *$ & $0.808^{* * *}$ & $0.605^{* * *}$ & $0.831 * * *$ & $0.574^{* * * * * ~}$ & $0.558 * * *$ & $0.520 * * *$ & $0.657 * * *$ \\
\hline \multicolumn{4}{|l|}{ Center/South/East } & $0.308 * *$ & $0.356 * *$ & $0.276 * *$ & $0.362^{* * *}$ & 0.211 & 0.091 & 0.186 & 0.177 \\
\hline \multicolumn{12}{|l|}{$\begin{array}{l}\text { Adamaoua/North/ } \\
\text { Far-North } \\
\text { (reference) }\end{array}$} \\
\hline \multicolumn{4}{|l|}{$\begin{array}{l}\text { Community } \\
\text { environmental } \\
\text { index }\end{array}$} & & & & & $0.117 * *$ & $0.078 * *$ & $0.074 *$ & 0.003 \\
\hline Log-Likelihood & $-5729.85 I$ & -5705.574 & -5739.404 & \multicolumn{2}{|c|}{-5198.523} & \multicolumn{2}{|c|}{-5183.880} & \multicolumn{2}{|c|}{-5205.653} & \multicolumn{2}{|c|}{-5177.527} \\
\hline Number of children & 3321 & 3321 & 3321 & \multicolumn{2}{|c|}{3321} & \multicolumn{2}{|c|}{3321} & \multicolumn{2}{|c|}{3321} & \multicolumn{2}{|c|}{3321} \\
\hline Number of clusters & 350 & 350 & 350 & \multicolumn{2}{|c|}{350} & \multicolumn{2}{|c|}{350} & \multicolumn{2}{|c|}{350} & \multicolumn{2}{|c|}{350} \\
\hline \multicolumn{12}{|c|}{ Random-effects parameters } \\
\hline $\begin{array}{l}\text { Between-individual } \\
\text { variance }(95 \mathrm{Cl})\end{array}$ & $\begin{array}{c}1.749(1.663- \\
1.84 I)\end{array}$ & $\begin{array}{c}1.745(1.659- \\
1.836)\end{array}$ & $\begin{array}{c}1.740(1.654- \\
1.830)\end{array}$ & \multicolumn{2}{|c|}{$1.30(1.232-1.363)$} & \multicolumn{2}{|c|}{$\begin{array}{l}1.285(1.221- \\
1.352)\end{array}$} & \multicolumn{2}{|c|}{$\begin{array}{c}1.300(1.236- \\
1.367)\end{array}$} & $1.281(1.2$ & $218-1.348)$ \\
\hline $\begin{array}{l}\text { Between-cluster } \\
\text { variance }(95 \mathrm{Cl})\end{array}$ & $\begin{array}{c}0.132(0.089- \\
0.196)\end{array}$ & $\begin{array}{l}0.095(0.059- \\
0.153)\end{array}$ & $\begin{array}{l}0.172(0.124- \\
0.239)\end{array}$ & $\begin{array}{r}0.054 \\
0.0\end{array}$ & $\begin{array}{l}0.031- \\
97)\end{array}$ & $\begin{array}{r}0.053( \\
0.0\end{array}$ & $\begin{array}{l}0.030- \\
97)\end{array}$ & $\begin{array}{r}0.0572 \\
0.0\end{array}$ & $\begin{array}{l}(0.033- \\
99)\end{array}$ & $0.052(0.0$ & $28-0.094)$ \\
\hline
\end{tabular}

Notes: -Each model (except for models 3 and 6) was estimated twice; for the first estimation, economic status and maternal health-seeking behavior were included as continuous variables, all other variables remaining unchanged, and for the second estimation, the quintiles of these variables were included; the table reports coefficients on other variables for the second estimation. A dummy indicator for missing values was also included for each variable with missing values. $\mathrm{Cl}$ denotes confidence interval.

-Statistical significance: *: $\mathrm{P}<0.10$; **: $\mathrm{p}<0.05 ; * * * \mathrm{p}<0.001$ 
Table 6: Multilevel linear regression estimates of the effects of socioeconomic and environmental factors on height-for-age z-score

\begin{tabular}{|c|c|c|c|c|c|c|c|c|c|c|c|c|c|c|}
\hline & \multicolumn{2}{|c|}{ Model I } & \multicolumn{2}{|c|}{ Model 2} & \multicolumn{2}{|c|}{ Model 3} & \multicolumn{2}{|c|}{ Model 4} & \multicolumn{2}{|c|}{ Model 5} & \multicolumn{2}{|c|}{ Model 6} & \multicolumn{2}{|c|}{ Model 7} \\
\hline & 1991 & 1998 & 1991 & 1998 & 1991 & 1998 & 1991 & 1998 & 1991 & 1998 & 1991 & 1998 & 1991 & 1998 \\
\hline \multicolumn{15}{|c|}{ Household economic status } \\
\hline \multicolumn{15}{|c|}{$\begin{array}{l}\text { Ist quintile } \\
\text { (reference) }\end{array}$} \\
\hline $2^{\text {nd }}$ quintile & 0.163 & $0.241^{\text {*** }}$ & 0.172 & $0.213^{*}$ & & & 0.181 & $0.248 * *$ & 0.140 & $0.248^{* *}$ & & & 0.147 & $0.24 I^{* *}$ \\
\hline $3^{\text {rd }}$ quintile & -0.186 & 0.120 & -0.171 & 0.113 & & & -0.115 & 0.143 & -0.152 & 0.134 & & & -0.141 & 0.144 \\
\hline $4^{\text {th }}$ quintile & 0.154 & $0.312^{* *}$ & 0.147 & $0.298 * *$ & & & 0.107 & $0.300 * *$ & -0.023 & $0.277^{* *}$ & & & -0.025 & $0.305^{* *}$ \\
\hline $5^{\text {th }}$ quintile & $0.429 * *$ & $0.560 * * *$ & * $0.384 * *$ & $0.550 * * *$ & & & $0.317^{* *}$ & $0.502^{* * *}$ & 0.067 & $0.439 * *$ & & & 0.047 & $0.478^{* *}$ \\
\hline Continuous & $0.250 * * *$ & $0.245^{* * *}$ & $* 0.221 * * *$ & $0.239 * * *$ & & & $0.146^{* *}$ & $0.206 * *$ & 0.011 & $0.160^{* *}$ & & & -0.007 & $0.176^{* *}$ \\
\hline \multicolumn{15}{|c|}{ Maternal health-seeking behavior } \\
\hline \multicolumn{15}{|c|}{$\begin{array}{l}\text { Ist quintile } \\
\text { (reference) }\end{array}$} \\
\hline $2^{\text {nd }}$ quintile & $0.275^{*}$ & $0.295^{\text {*** }}$ & 0.217 & 0.160 & & & 0.146 & 0.129 & 0.167 & 0.124 & & & 0.175 & 0.102 \\
\hline $3^{\text {rd }}$ quintile & 0.147 & 0.135 & 0.054 & -0.111 & & & 0.117 & -0.037 & 0.128 & -0.035 & & & 0.117 & -0.089 \\
\hline $4^{\text {th }}$ quintile & $0.301 *$ & $\left.0.36\right|^{* *}$ & 0.132 & 0.054 & & & 0.234 & $0.253^{*}$ & 0.214 & $0.248^{*}$ & & & 0.193 & 0.167 \\
\hline $5^{\text {th }}$ quintile & $0.326 * *$ & $0.365^{* *}$ & 0.112 & -0.045 & & & 0.259 & $0.260 *$ & 0.204 & 0.237 & & & 0.155 & 0.117 \\
\hline Continuous & $0.087 *$ & $0.123^{* *}$ & 0.06 & -0.007 & & & 0.083 & $0.108 * *$ & 0.060 & $0.103^{* *}$ & & & 0.050 & 0.071 \\
\hline \multicolumn{15}{|c|}{ Household environment } \\
\hline \multicolumn{15}{|c|}{ Water } \\
\hline Poor (reference) & & & & & & & & & & & & & & \\
\hline Medium & & & & & $0.189 *$ & 0.146 & & & 0.119 & -0.026 & & & 0.073 & 0.014 \\
\hline Good & & & & & $0.38 I^{* *}$ & 0.090 & & & $0.254^{* *}$ & -0.134 & & & 0.190 & -0.094 \\
\hline Sanitation & & & & & & & & & & & & & & \\
\hline Poor (reference) & & & & & & & & & & & & & & \\
\hline Medium & & & & & 0.045 & $0.496 * *$ & & & -0.080 & $0.399 * *$ & & & -0.150 & $0.402 * *$ \\
\hline Good & & & & & 0.125 & $0.219^{* *}$ & & & 0.089 & 0.042 & & & 0.076 & 0.051 \\
\hline Cooking fuel & & & & & & & & & & & & & & \\
\hline Poor (reference) & & & & & & & & & & & & & & \\
\hline Good & & & & & $0.380^{* * * *}$ & $0.187 *$ & & & $0.292 * *$ & 0.059 & & & $0.245^{* *}$ & 0.064 \\
\hline Maternal educat & & & & & & & & & & & & & & \\
\hline $\begin{array}{l}\text { No education } \\
\text { (reference) }\end{array}$ & & & & & & & & & & & & & & \\
\hline Primary & & & $0.206 *$ & $0.356 * * *$ & & & & & & & 0.141 & $0.258 * *$ & 0.100 & 0.199 \\
\hline Secondary or + & & & $0.374 * *$ & $0.535^{* * * *}$ & & & & & & & $0.24 I^{*}$ & $0.459 * * *$ & 0.150 & $0.313 * *$ \\
\hline Maternal age at & jirth (yrs) & & & & & & & & & & & & & \\
\hline$<20$ (reference) & & & & & & & & & & & & & & \\
\hline $20-29$ & & & & & & & 0.015 & 0.100 & -0.004 & 0.098 & 0.012 & 0.129 & -0.001 & 0.106 \\
\hline $30-49$ & & & & & & & 0.044 & 0.137 & 0.040 & 0.131 & 0.047 & $0.188 *$ & 0.051 & 0.157 \\
\hline Maternal marita & status & & & & & & & & & & & & & \\
\hline Married monogamy & & & & & & & $0.223 * *$ & -0.022 & $0.212 * *$ & -0.029 & $0.230^{* *}$ & -0.032 & $0.222^{\text {** }}$ & -0.030 \\
\hline Other (reference) & & & & & & & & & & & & & & \\
\hline Child sex & & & & & & & & & & & & & & \\
\hline Male & & & & & & & -0.065 & $-0.198 * *$ & -0.052 & $-0.198 * *$ & -0.065 & $-0.196 * *$ & -0.056 & $-0.198^{* *}$ \\
\hline Female (reference) & & & & & & & & & & & & & & \\
\hline Child age (montl & & & & & & & & & & & & & & \\
\hline 0-5 (reference) & & & & & & & & & & & & & & \\
\hline $6-11$ & & & & & & & $-0.727 * * *$ & $-0.612 * * *$ & $-0.74 \mid * * *$ & $-0.620 * * *$ & 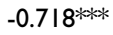 & $-0.589 * * *$ & $-0.745 * * *$ & $-0.614 * * *$ \\
\hline $12-23$ & & & & & & & $-1.511 * * *$ & $-1.770 * * *$ & $-1.497 * * *$ & $-1.769 * * *$ & $-1.492^{* * * *}$ & $-1.745^{* * * *}$ & $-1.497 * * *$ & $-1.752 * * *$ \\
\hline $24-35$ & & & & & & & $-1.664 * * *$ & $-1.743 * * *$ & $-1.653^{*} * *$ & $-1.743 * * *$ & 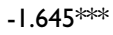 & $-1.707^{* * * *}$ & $-1.656 * * *$ & $-1.727^{* * *}$ \\
\hline Birth size & & & & & & & & & & & & & & \\
\hline Small (reference) & & & & & & & & & & & & & & \\
\hline Average & & & & & & & $0.302 * *$ & 0.120 & $0.315^{* * *}$ & 0.124 & $0.325^{* * *}$ & 0.114 & $0.329 * *$ & 0.124 \\
\hline Large & & & & & & & $0.552 * * *$ & $0.352^{* * * *}$ & $0.567^{* * * *}$ & $0.124 * * *$ & $0.566^{* * * * *}$ & 0.356 **** & $0.572^{* * *}$ & 0.351 **** \\
\hline Breastfeeding du & ration & & & & & & & & & & & & & \\
\hline Never breastfed & & & & & & & -0.258 & -0.687 & -0.258 & -0.691 & -0.190 & -0.679 & -0.221 & -0.652 \\
\hline Still breastfeeding & & & & & & & $-0.407^{*}$ & -0.412 & -0.335 & -0.343 & -0.313 & -0.410 & -0.297 & -0.307 \\
\hline $\begin{array}{l}\text { Breastfed 0-4 } \\
\text { months }\end{array}$ & & & & & & & 0.052 & -0.108 & 0.081 & -0.969 & 0.104 & -0.100 & 0.110 & -0.076 \\
\hline $\begin{array}{l}\text { Breastfed 5-6 } \\
\text { months (reference) }\end{array}$ & & & & & & & & & & & & & & \\
\hline Breastfed 7-18 & & & & & & & -0.027 & -0.103 & 0.019 & -0.041 & 0.036 & -0.111 & 0.046 & -0.013 \\
\hline
\end{tabular}


Table 6: Multilevel linear regression estimates of the effects of socioeconomic and environmental factors on height-for-age z-score

\begin{tabular}{|c|c|c|c|c|c|c|c|c|c|c|c|}
\hline \multicolumn{4}{|l|}{$\begin{array}{l}\text { Breastfed } 19 \\
\text { months or more }\end{array}$} & -0.213 & -0.189 & -0.144 & -0.123 & -0.142 & -0.179 & -0.095 & -0.077 \\
\hline \multicolumn{12}{|c|}{ Preceding birth interval } \\
\hline \multicolumn{4}{|c|}{ First born child } & 0.032 & -0.074 & 0.029 & -0.075 & 0.022 & -0.100 & 0.030 & -0.088 \\
\hline \multicolumn{4}{|l|}{$7-18$ months } & -0.021 & -0.233 & -0.036 & -0.237 & -0.023 & $-0.274^{*}$ & -0.033 & $-0.253^{*}$ \\
\hline \multicolumn{4}{|l|}{ 19-23 months } & -0.152 & $-0.224 * *$ & -0.129 & $-0.22 I^{* *}$ & -0.130 & $-0.220^{*}$ & -0.125 & $-0.227^{* *}$ \\
\hline \multicolumn{12}{|l|}{$\begin{array}{l}24 \text { months or more } \\
\text { (reference) }\end{array}$} \\
\hline \multicolumn{12}{|l|}{ Place of residence } \\
\hline \multicolumn{4}{|l|}{ Yaounde/Douala } & & & & & -0.092 & 0.276 & -0.198 & 0.175 \\
\hline \multicolumn{4}{|l|}{ Intermediate cities } & & & & & $-0.206^{*}$ & 0.158 & $-0.245^{*}$ & 0.041 \\
\hline \multicolumn{12}{|l|}{ Rural (reference) } \\
\hline \multicolumn{12}{|l|}{ Region } \\
\hline \multicolumn{4}{|l|}{ West/Littoral } & 0.218 & $0.293 * *$ & 0.185 & $0.273 * *$ & 0.069 & 0.152 & 0.052 & 0.160 \\
\hline \multicolumn{4}{|l|}{$\begin{array}{l}\text { North-West/ } \\
\text { South-West }\end{array}$} & 0.143 & $0.400 * *$ & 0.150 & $0.406 * *$ & 0.028 & $0.268 * *$ & 0.025 & $0.315^{* *}$ \\
\hline \multicolumn{4}{|l|}{ Center/South/East } & $0.25 I^{*}$ & 0.175 & $0.217^{*}$ & 0.161 & 0.096 & -0.013 & 0.072 & 0.024 \\
\hline \multicolumn{12}{|l|}{$\begin{array}{l}\text { Adamaoua/North/ } \\
\text { Far-North } \\
\text { (reference) }\end{array}$} \\
\hline \multicolumn{4}{|l|}{$\begin{array}{l}\text { Community } \\
\text { environmental } \\
\text { index }\end{array}$} & & & & & $0.156 * * *$ & 0.021 & $0.103 * *$ & -0.049 \\
\hline Log-Likelihood & -5951.931 & -5939.119 & -5953.087 & \multicolumn{2}{|c|}{-5594.023} & \multicolumn{2}{|c|}{-5578.431} & \multicolumn{2}{|c|}{-5600.445} & \multicolumn{2}{|c|}{$-557 \mid .327$} \\
\hline Number of children & 3321 & 3321 & 3321 & \multicolumn{2}{|c|}{3321} & \multicolumn{2}{|c|}{3321} & \multicolumn{2}{|c|}{3321} & \multicolumn{2}{|c|}{3321} \\
\hline Number of clusters & 350 & 350 & 350 & \multicolumn{2}{|c|}{350} & \multicolumn{2}{|c|}{350} & \multicolumn{2}{|c|}{350} & \multicolumn{2}{|c|}{350} \\
\hline \multicolumn{12}{|c|}{ Random-effects parameters } \\
\hline $\begin{array}{l}\text { Between individual } \\
\text { variance }(95 \mathrm{Cl})\end{array}$ & $2.059(1.958-2.165$ & $\begin{array}{c}2.055(1.954- \\
2.161)\end{array}$ & $\begin{array}{c}2.057(1.957- \\
2.163)\end{array}$ & \multicolumn{2}{|c|}{$\begin{array}{c}1.660(1.578- \\
1.746)\end{array}$} & \multicolumn{2}{|c|}{$\begin{array}{c}1.649(1.567- \\
1.734)\end{array}$} & \multicolumn{2}{|c|}{$\begin{array}{l}1.675(1.592- \\
1.762)\end{array}$} & $\begin{array}{r}1.647 \\
1.7\end{array}$ & $\begin{array}{l}1.565- \\
32)\end{array}$ \\
\hline $\begin{array}{l}\text { Between cluster } \\
\text { variance }(95 \mathrm{Cl})\end{array}$ & $\begin{array}{c}0.059(0.029- \\
0.118)\end{array}$ & $\begin{array}{c}0.042(0.017- \\
0.105)\end{array}$ & $\begin{array}{c}0.063(0.033- \\
0.121)\end{array}$ & $\begin{array}{r}0.047 \\
0.1\end{array}$ & $\begin{array}{l}(0.022- \\
00)\end{array}$ & $\begin{array}{r}0.041 \\
0.0\end{array}$ & $\begin{array}{l}0.018- \\
95)\end{array}$ & $\begin{array}{r}0.036 \\
0.0\end{array}$ & $\begin{array}{l}0.015- \\
90)\end{array}$ & $\begin{array}{r}0.034 \\
0.0\end{array}$ & $\begin{array}{l}0.013- \\
90)\end{array}$ \\
\hline
\end{tabular}

Notes: -Each model (except for models 3 and 6) was estimated twice; for the first estimation, economic status and maternal health-seeking behavior were included as continuous variables, all other variables remaining unchanged, and for the second estimation, the quintiles of these variables were included; the table reports coefficients on other variables for the second estimation. A dummy indicator for missing values was also included for each variable with missing values. $\mathrm{Cl}$ denotes confidence interval.

-Statistical significance: *: $\mathrm{P}<0.10$; **: $\mathrm{p}<0.05$; ***: $\mathrm{p}<0.001$ 
Table 7: Change in the coefficients of selected variables between I99I and I998

\begin{tabular}{|c|c|c|c|c|}
\hline & \multicolumn{2}{|c|}{ Weight-for-age z-score } & \multicolumn{2}{|c|}{ Height-for-age z-score } \\
\hline & Unadjusted model & Adjusted model & Unadjusted model & Adjusted model \\
\hline \multicolumn{5}{|l|}{ Household Economic status } \\
\hline \multicolumn{5}{|l|}{ |st quintile (reference) } \\
\hline $2^{\text {nd }}$ quintile & -0.027 & $-0.017(-0.009)$ & 0.081 & $0.094(0.107)$ \\
\hline $3^{\text {rd }}$ quintile & 0.194 & $0.174(0.172)$ & $0.302 *$ & $0.286 *(0.286 *)$ \\
\hline $4^{\text {th }}$ quintile & 0.087 & $0.337^{*}\left(0.322^{*}\right)$ & 0.179 & $0.331 *(0.301)$ \\
\hline $5^{\text {th }}$ quintile & 0.238 & $0.566 * *(0.526 * *)$ & 0.164 & $0.43 I^{*}\left(0.37 I^{*}\right)$ \\
\hline Continuous & 0.055 & $0.219 * *\left(0.214^{* *}\right)$ & -0.017 & $0.183(0.150)$ \\
\hline \multicolumn{5}{|l|}{ MHSB } \\
\hline \multicolumn{5}{|l|}{ | st quintile (reference) } \\
\hline $2^{\text {nd }}$ quintile & -0.086 & $-0.196(-0.160)$ & 0.057 & $-0.073(-0.043)$ \\
\hline $3^{\text {rd }}$ quintile & -0.144 & $-0.372 *\left(-0.308^{*}\right)$ & 0.007 & $-0.206(-0.163)$ \\
\hline $4^{\text {th }}$ quintile & -0.044 & $-0.232(-0.150)$ & 0.059 & $-0.026(0.034)$ \\
\hline $5^{\text {th }}$ quintile & -0.142 & $-0.358^{*}(-0.272)$ & 0.106 & $-0.038(0.033)$ \\
\hline Continuous & -0.039 & $-0.108(-0.068)$ & 0.022 & $0.02 I(0.043)$ \\
\hline \multicolumn{5}{|l|}{ Household environment } \\
\hline \multicolumn{5}{|l|}{ Water } \\
\hline \multicolumn{5}{|l|}{ Poor (reference) } \\
\hline Medium & -0.018 & $-0.036(-0.087)$ & -0.042 & $-0.059(-0.145)$ \\
\hline Good & -0.215 & $-0.257\left(-0.3 \mid 2^{* *}\right)$ & $-0.250 *$ & $-0.284\left(-0.387^{* *}\right)$ \\
\hline \multicolumn{5}{|l|}{ Sanitation } \\
\hline \multicolumn{5}{|l|}{ Poor (reference) } \\
\hline Medium & $0.552^{* * * *}$ & $0.342(0.310)$ & 0.078 & $0.553^{* *}(0.479 * *)$ \\
\hline Good & -0.084 & $-0.155(-0.169)$ & -0.031 & $-0.024(-0.047)$ \\
\hline \multicolumn{5}{|l|}{ Cooking fuel } \\
\hline \multicolumn{5}{|l|}{ Poor (reference) } \\
\hline Good & -0.114 & $-0.101(-0.127)$ & $-0.20 I^{*}$ & $-0.180(-0.233 *)$ \\
\hline \multicolumn{5}{|l|}{ Maternal education } \\
\hline \multicolumn{5}{|l|}{ No education (reference) } \\
\hline Primary & 0.142 & $0.232(0.167)$ & 0.066 & $0.099(0.117)$ \\
\hline Secondary or + & 0.159 & $0.229(0.193)$ & 0.074 & $0.162(0.218)$ \\
\hline \multicolumn{5}{|l|}{ Maternal marital status } \\
\hline Married monogamy & $-0.223 * *$ & $-0.212^{*}\left(-0.147^{*}\right)$ & $-0.295^{* *}$ & $-0.25 I^{* *}\left(-0.24 I^{* *}\right)$ \\
\hline \multicolumn{5}{|l|}{ Other (reference) } \\
\hline \multicolumn{5}{|l|}{ Child sex } \\
\hline Male & $-0.187^{* *}$ & $-0.137^{*}\left(-0.141^{*}\right)$ & -0.154 & $-0.142(-0.145)$ \\
\hline \multicolumn{5}{|l|}{ Female (reference) } \\
\hline \multicolumn{5}{|l|}{ Child age (months) } \\
\hline $0-5$ (reference) & & & & \\
\hline $6-11$ & -0.129 & $-0.111(-0.113)$ & 0.089 & $0.130(0.120)$ \\
\hline $12-23$ & $-0.216^{*}$ & $-0.225 *(-0.240 *)$ & $-0.320 * *$ & $-0.255^{*}(-0.27 \mid *)$ \\
\hline $24-35$ & -0.204 & $-0.257(-0.275)$ & -0.146 & $-0.071(-0.090)$ \\
\hline Place of residence & & & & \\
\hline Yaounde/Douala & -0.160 & $0.039(-0.007)$ & -0.139 & $0.373(0.368)$ \\
\hline Intermediate cities & 0.071 & $0.102(0.141)$ & 0.084 & $0.286\left(0.364^{* *}\right)$ \\
\hline Rural (reference) & & & & \\
\hline Region & & & & \\
\hline West/Littoral & -0.125 & $0.043(-0.068)$ & 0.091 & $0.107(0.082)$ \\
\hline North-West/South-West & 0.107 & $0.137(-0.016)$ & 0.237 & $0.291(0.240)$ \\
\hline Center/South/East & 0.053 & $-0.008(-0.120)$ & 0.003 & $-0.048(-0.109)$ \\
\hline Adamaoua/North/Far-North (reference) & & & & \\
\hline Community environmental index & -0.032 & $-0.070(-0.040)$ & -0.049 & $-0.152^{* *}\left(-0.134^{* *}\right)$ \\
\hline
\end{tabular}

Notes: The unadjusted models included only the independent variable of interest; the adjusted models additionally included all other independent variables used in this study (see tables 5-6, model 7); values in parentheses were estimated from model 5 for all variables in the table except for maternal education, place of residence, region and community environmental index which were estimated from model 6 . Only selected variables are presented in the table.

-Statistical significance: *: $\mathrm{P}<0.10$; **: $\mathrm{p}<0.05 ; * * *: \mathrm{p}<0.001$ 
Table 8: Age-specific effects of household economic status (ES)

\begin{tabular}{|c|c|c|c|c|c|c|c|c|}
\hline \multirow[b]{3}{*}{$\begin{array}{l}\text { Child age groups } \\
\text { (months) }\end{array}$} & \multicolumn{4}{|c|}{ Weight-for-age z-score } & \multicolumn{4}{|c|}{ Height-for-age z-score } \\
\hline & \multicolumn{2}{|c|}{1991} & \multicolumn{2}{|c|}{1998} & \multicolumn{2}{|c|}{1991} & \multicolumn{2}{|c|}{1998} \\
\hline & $\begin{array}{l}\text { Unadjusted } \\
\text { model }\end{array}$ & $\begin{array}{l}\text { Adjusted } \\
\text { model }\end{array}$ & $\begin{array}{l}\text { Unadjusted } \\
\text { model }\end{array}$ & $\begin{array}{l}\text { Adjusted } \\
\text { model }\end{array}$ & $\begin{array}{l}\text { Unadjusted } \\
\text { model }\end{array}$ & $\begin{array}{l}\text { Adjusted } \\
\text { model }\end{array}$ & $\begin{array}{l}\text { Unadjusted } \\
\text { model }\end{array}$ & $\begin{array}{l}\text { Adjusted } \\
\text { model }\end{array}$ \\
\hline & \multicolumn{8}{|c|}{ Effects of ES } \\
\hline $0-5$ & 0.095 & -0.153 & 0.055 & -0.047 & -0.069 & $-0.275^{* *}$ & $0.313 * *$ & $0.202 *$ \\
\hline $6-11$ & $0.331 * * *$ & 0.127 & $0.427 * * *$ & $0.295^{* *}$ & $0.260 * *$ & 0.087 & $0.194^{*}$ & 0.062 \\
\hline $12-23$ & $0.404 * * *$ & $0.176 * *$ & $0.503 * * *$ & $0.36 I^{* * * *}$ & $0.473 * * *$ & $0.268^{* *}$ & $0.408 * * *$ & $0.269 * *$ \\
\hline \multirow[t]{2}{*}{$24-35$} & $0.399 * * *$ & $0.177^{* *}$ & $0.445^{* * *}$ & $0.306 * * *$ & $0.510 * * *$ & $0.332 * * *$ & $0.38 \mathrm{I} * * *$ & $0.225 * *$ \\
\hline & \multicolumn{8}{|c|}{ Age-difference in ES effects (each age group is compared to $0-5$ months) } \\
\hline \multicolumn{9}{|l|}{$0-5$ (reference) } \\
\hline $6-11$ & $0.236 *$ & $0.280 * *$ & $0.37 \mid * *$ & $0.341 * *$ & $0.329 * *$ & $0.363 * *$ & -0.118 & -0.140 \\
\hline $12-23$ & $0.308^{* *}$ & $0.330 * *$ & $0.448 * * *$ & $0.407 * * *$ & $0.542 * * *$ & $0.543 * * *$ & 0.094 & 0.067 \\
\hline $24-35$ & $0.304 * *$ & $0.330 * *$ & $0.389 * * *$ & $0.353 * * *$ & $0.579 * * *$ & $0.608 * * *$ & 0.068 & 0.023 \\
\hline
\end{tabular}

Notes: The unadjusted models for "ES effects" included child age groups and the interaction terms between child age groups and ES; the adjusted models additionally included the independent variables used in model 4 of tables 5-6 (model 4 was used to avoid correlation of ES with variables such as education and community environmental index; however the full model (model 7) yielded results very similar to those presented in the table). The unadjusted models for "age-difference in ES effects" included child age groups, ES, and the interaction terms between child age groups and ES (except for the interaction term between $0-5$ months and ES); the adjusted models additionally included the independent variables used in model 4 of tables 5-6. These models were estimated for the years 1991 and 1998 simultaneously.

-Statistical significance: *: $\mathrm{P}<0.10$; **: $\mathrm{p}<0.05 ;{ }^{* * *}: \mathrm{p}<0.001$

There are some limitations in the data used for this analysis. Since this work relied on survey-based data, selection and recall bias could affect the results. Using a measured anthropometric indicator of nutritional outcome, however, eliminates one of the most important sources of bias. The measure of community environmental status used in this study is only a proxy of what the real environmental conditions and infrastructure are, as factors such as water stagnation, garbage accumulation and distance to electricity grid, which capture the quality of environment, were not available in our data. The availability of those indicators may have produced a better estimate of the effect of environmental infrastructure on child nutritional health. Other limitations of this work stem from the amount of missing data. Weight-for-age and height-for-age z-scores were calculated for only $81 \%$ and $85 \%$ of children under 3 years old in 1991 and 1998 respectively. Although the fraction of observations with missing value was relatively low, we found missing data to be correlated with some factors including household economic status and hygiene, MHSB, child age, and place and region of residence, a potential source of bias.

\section{Conclusion}

The age-specific effect of economic status on child nutritional status found in this study suggests that children aged $0-5$ months should be distinguished from older children in the analysis of factors associated with child nutrition outcomes, with an attention to the possible role of breastfeeding in early ages, as it has been proven to have great benefits to child health and survival [54-56].
Socioeconomic and environmental effects may vary across age groups, motivating age-specific analysis of factors affecting health. This study shows that child nutritional health is simultaneously influenced by household and community factors, and can be addressed to some extent, but not entirely, by interventions at either level. Low nutritional status is more likely in children of low socioeconomic status, and children at risk are clustered in dry regions and within community with poor environmental status. Inclusion of household and community factors is needed in addressing the issue of child health in Cameroon, and will assist in designing more effective context-specific intervention programs.

\section{Competing interests}

The author(s) declare that they have no competing interests.

\section{Authors' contributions}

$\mathrm{RP}$ contributed to the study design, the data analysis and the writing of the manuscript. ME and JAS supervised all parts of the study and contributed to the methodology and writing of the manuscript. All authors read and approved the final version of the manuscript.

\section{Acknowledgements}

We thank two referees and seminar participants at the Harvard Center for Population and Development Studies for very helpful comments on previous versions of this paper. This work was sponsored by the National Institute on Aging (Grant POI-AG I7625). Tetanye Ekoe and Claudine Passo provided useful literature on child nutritional health in Cameroon. We 
thank Ajay Tandon and Emmanuela Gakidou for valuable inputs to the construction of the economic status and MHSB index.

\section{References}

I. Ezzati M, Lopez AD, Rodgers A, Vander Hoorn S, Murray C], The Comparative Risk Assessment Collaborating Group: Selected major risk factors and global and regional burden of disease. Lancet 2002, 360: I347-1360.

2. Kemgo P: Allaitement et état nutritionnel des enfants et des femmes. In Cameroun: Enquête Démographique et de Santé 1998 Edited by: Bureau Central des Recensements et des Etudes de Population. Yaoundé; 1999:135-149.

3. Barrère B: Mortalité des enfants de moins de cinq ans. In Cameroun: Enquête démographique et de santé 1991 Edited by: Direction Nationale du Deuxième Recensement Général de la Population et de I'Habitat. Yaoundé; 1992: I31-135.

4. Libité PR: Mortalité des enfants. In Cameroun: Enquête démographique et de santé 2004 Edited by: Bureau Central des Recensements et des Etudes de Population. Yaoundé; 2004:213-220.

5. de Onis M, Blossner M, Borghi E, Frongillo EA, Morris R: Estimates of global prevalence of childhood underweight in 1990 and 20 I5. JAMA 2004, 29I(2I):2600-06

6. Popkin BM: The nutrition transition in the developing world. Development Policy Review 2003, 2 I (5-6):58I-597.

7. Scrimshaw NS, Taylor CE, Gordon JE: Interaction of nutrition and infection. World Health Organization 1968. Monograph Series 57

8. Pelletier DL: Malnutrition, morbidity and child mortality in developing countries. In Too young to die: Genes or Gender? Edited by: United Nations. New York: Department of Economic and Social Affairs, Population Division; 1998:109-132.

9. Pelletier DL, Frongillo EA Jr, Habicht JP: Epidemiologic evidence for a potentiating effect of malnutrition on child mortality. American Journal of Public Health 1993, 83: I130-1133.

10. Webb Webb P, Block S: Nutrition information and formal schooling as inputs to child nutrition. Economic Development and cultural change 2004, 52(4):. 0300I4

II. Merchant AT, Jones C, Kiure A, Kupka A, Fitzmaurice G, Herrera MG, Fawzi WW: Water and sanitation associated with improved child growth. European Journal of Clinical Nutrition 2003, 57:I562-1568.

12. Waters H, Saadah F, Surbakti S, Heywood P: Weight-for-age malnutrition in Indonesian children, 1992-1999. Int J Epidemio 2004, 33:1-7.

13. Frongillo EA Jr, de Onis M, Hanson K: Socioeconomic and demographic factors are associated with Worldwide patterns of stunting and wasting. Journal of Development 1997, I 27( I 2):2302-09.

14. World Bank: Nutritional status and poverty in sub-Saharan Africa. Findings Africa Region World Bank 1998: 108.

15. Mosley WH, Chen LC: An Analytical Framework for the Study of Child Survival in Developing Countries. Population and Development Review 1984:25-45.

16. Gwatkin DR, Rustein S, Johnson K, Pande R, Wagstaff A: Socioeconomic differences in health, nutrition, and population. World Bank/HNP Discussion Papers 2000.

17. Sahn DE, Alderman H: On the determinants of nutrition in Mozambique: The importance of age-specific effects. World Development 1997, 25(4):577-588.

18. Case A, Lubotsky D, Paxson C: Economic status and health in childhood: the origins of gradient. NBER working paper 200I, 8344:.

19. Fotso JC, Kuate DB: Socioeconomic inequalities in early childhood malnutrition and morbidity: modification of the household-level effects by the community SES. Health \& place 2005 , I I (3):205-225.

20. Lape MBome, Garba Messomo MT, Rikong Adie H, Sajo Nana EC, Noubi L, Njinang KM, Fotso M: Enquête Nutritionnelle dans le district de santé de Moloundou. Rapport technique Yaoundé: Ministère de la Recherche Scientifique et Technique; 2000.

21. Ganyam NG: Nutritional Status of Children (0-5 years) in Bali Sub-Division: Anthropometry and risk factors. Doctor of Medicine thesis, Universty of Yaounde I, Faculty of Medicine and Biomedical Sciences 1998.

22. Piechulek $\mathrm{H}$, Mendoza JA: Les enfants de poids insuffisant à la naissance: Les exigences d'un programme de surveillance nutritionnelle. Exemple: La zone rurale de la province du Littoral (Cameroun). Médecine d'Afrique Noire 1996, 43(2):67-70.

23. Kuate DB, Ed: Nutrition and child health in Cameroon Westmount: Price-Patterson Ltd, Canadian publishers; $200 \mathrm{I}$.

24. Gibbons LS: Income distribution, poverty and consumer preferences in Cameroon Washington: World Bank; 199I. CMR00613

25. Bureau of Statistics and National Accounts: Living conditions and poverty in Cameroon in 200I World Bank; 2002. CMR035I8

26. [http://www.measuredhs.com]. (access 09//5/2003)

27. Fishman SM, Caulfield LE, de Onis M, Blössner M, Hyder AA, Mullany L, Black RE: Childhood and maternal underweight. In Comparative Quantification of Health Risks: The Global and Regional Burden of Disease Attributable to Selected Major Risk Factors Edited by: Ezzati M, Lopez AD, Rodgers A, Murray CJL. Geneva:World Health Organisation; 2004:39-|3I.

28. Ferguson BD, Tandon A, Gakidou E, Murray CJL: Estimating permanent income using indicator variables. In Health Systems Performance Assessment: Debates, Methods and Empiricism Edited by: Murray CJL, Evans DB Geneva. World Health Organization; 2003:747-760.

29. Kawachi I, Berkman LF, eds: Neighborhoods and Health New York: Oxford University Press; 2003.

30. Subramanian SV, Chen J, Rehkopf D, Waterman PD, Krieger N Racial disparities in context: a multilevel analysis of neighborhood variations in poverty and excess mortality among black populations. American Journal of Public Health 2005, 95(2):260-265. [Errata: 95, 3: 375]

31. Jones K, Duncan C: Individuals and their ecologies: analyzing the geography of chronic illness within a multilevel modeling framework. Health \& Place 1995, I(I):27-40.

32. Golstein $\mathrm{H}$ : Multilevel models in educational and social research London: Charles Griffin; 1987.

33. Gubry P, Lamlenn BS, Ngwé E, Tchégho JM, Timnou JP, Véron Jacques , eds: Le retour au village Une solution à la crise économique au Cameroun? Paris: L'Harmattan, MINREST, IFORD, CEPED; 1996.

34. Beauchemin C, Bocquier P: Migration and urbanization in Francophone West Africa: A review of the recent empirical evidence. Développement, Institutions \& Analyses de Long Terme Working paper 2003:DT/2003/09.

35. Sunderlin WD, Pokam J: Economic crisis and forest cover change in Cameroon: The roles of migration, crop diversification, and gender division of labor. Economic Development and Cultural Change 2002, 50:58I-606.

36. Libité PR: Fécondité. In Cameroun: Enquête démographique et de santé 199/ Edited by: Direction Nationale du Deuxième Recensement Général de la Population et de l'Habitat. Yaoundé; 1992:30-42.

37. Libité PR: Fécondité. In Cameroun: Enquête démographique et de santé 1998 Edited by: Bureau Central des Recensements et des Etudes de Population. Yaoundé; 1998:37-56.

38. Heston A, Summers R, Bettina A: Penn World Table Version 6.I Center for International Comparisons at the University of Pennsylvania (CICUP); 2002.

39. de Onis M, Frongillo EA, Blossner M: Is malnutrition declining? An analysis of changes in levels of child malnutrition since 1980. Bulletin of the World Health Organization 2000, 78: I222-I233.

40. Block SA, Kiess L, Webb P, Kosen S, Moench-Pfanner R, Bloem MW, Timmer CP: Macro shock and micro outcomes: child nutrition during Indonesia's crisis. Economic and Human Biology 2004, 2:21-44.

4I. Ezzati M, Vander Hoorn S, Lawes CMM, Leach R, James WPT, Lopez $A D$, Rodgers A, Murray CJL: Rethinking the "diseases of affluence" paradigm: global patterns of nutritional risks in relation to economic development. PloS Medecine 2005, 2(5):el 33.

42. Doak C, Adair LS, Bentley ME, Monteiro C, Popkin BM: The dual burden household and the nutrition transition paradox. International Journal of Obesity 2005, 29:129-136.

43. Jeyaseelan L, Lakshman M: Risk factors for malnutrition in South Indian children. J Biosoc Sci 1997, 29:93-100.

44. Masudi UJ: Covariates of child mortality in Mali: Does the Health-Seeking Behavior of the mother matter? J biosoc Sci 200I, 33:33-54.

45. Magnani RJ, Mock NB, Bertrand WE, Clay DC: Breastfeeding, water and sanitation, and childhood malnutrition in the Philippines. J Biosoc Sci 1993, 25:195-2II.

46. Alam DS, Marks GC, Baqui AH, Yunus M, Fuchs G]: Association between clinical type of diarrhea and growth of children 
under 5 years in rural Bangladesh. Int J Epidemio 2000, 29:916-921.

47. Guerrant RL, Schorling JB, McAuliffe JF, de Souza MA: Diarrhea as a cause and an effect of malnutrition: diarrhea prevents catch-up growth and malnutrition increases diarrhea frequency and duration. Am J Trop Med Hyg 1992, 47:28-35.

48. Black RE, Brown KH, Becker S: Effects of diarrhoea associated with specific enteropathogens on the growth of children in rural Bangladesh. Pediatrics 1984, 73:799-805.

49. Martorell R, Yarbrough C, Lechtig A, Habicht JP, Klein RE: Diarrheal diseases and growth retardation in preschool Guatemalan children. American Journal of Physical Anthropology 1975, 43:34I-346.

50. Boy E, Bruce N, Delgado H: Birth weight and exposure to kitchen wood smoke during pregnancy in rural Guatemala. Environmental Health Perspectives 2002, I I 0: 109-I I4.

5I. Ezzati M, Kammen MD: Indoor air pollution from biomass combustion and acute respiratory infections in Kenya: an exposure-response study. Lancet 200I, 358:619-624.

52. Smith KR, Samet JM, Romieu I, Bruce N: Indoor air pollution in Developing Countries and acute lower respiratory infections in Children. Thorax 2000, 55:518-532.

53. Kuate DB: Areal and socioeconomic differentials in infant and child mortality in Cameroon. Soc Sc Med 1996, 42(3):399-420.

54. Black RE, Victora CG: Optimal duration of exclusive breast feeding in low economic status countries. BM] 2002, 325: $1252-3$.

55. Arifeen S, Black RE, Antelman G, Baqui A, Caulfield L, Becker S: Exclusive breastfeeding reduces acute respiratory disease and diarrhoea deaths among infants in Dhaka slums. Pediatrics 200I, 108:E67.

56. Victora CG, Smith PG, Vaughan JP, Nobre LC, Lombardi C, Teixeira AM, Fuchs SM, Moreira LB, Gigante LP, Barros FC: Evidence for protection by breast-feeding against infant deaths from infectious diseases in Brazil. Lancet 1987, 2(8554):3|9-32I.

\section{Pre-publication history}

The pre-publication history for this paper can be accessed here:

http://www.biomedcentral.com/1471-2458/6/98/prepub

\section{Publish with Bio Med Central and every scientist can read your work free of charge}

"BioMed Central will be the most significant development for disseminating the results of biomedical research in our lifetime. "

Sir Paul Nurse, Cancer Research UK

Your research papers will be:

- available free of charge to the entire biomedical community

- peer reviewed and published immediately upon acceptance

- cited in PubMed and archived on PubMed Central

- yours - you keep the copyright 